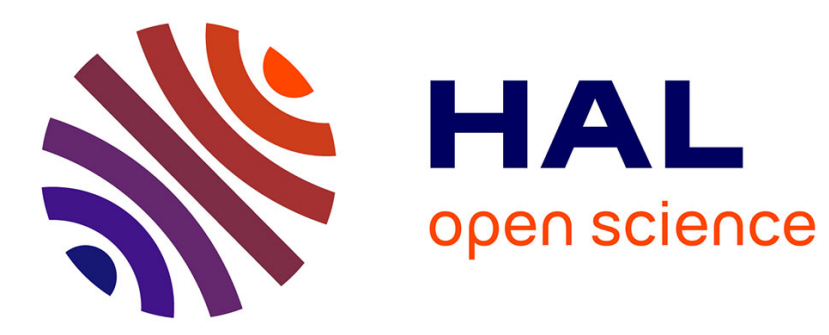

\title{
Comparison of existing chloride ingress models within concretes exposed to seawater
}

\author{
Sylvain Pradelle, Mickaël Thiery, Véronique Baroghel Bouny
}

\section{To cite this version:}

Sylvain Pradelle, Mickaël Thiery, Véronique Baroghel Bouny. Comparison of existing chloride ingress models within concretes exposed to seawater. Materials and structures, 2016, 49 (11), pp.4497-4516. $10.1617 / \mathrm{s} 11527-016-0803-y$. hal-01266882

\section{HAL Id: hal-01266882 \\ https://hal.science/hal-01266882}

Submitted on 10 Jan 2018

HAL is a multi-disciplinary open access archive for the deposit and dissemination of scientific research documents, whether they are published or not. The documents may come from teaching and research institutions in France or abroad, or from public or private research centers.
L'archive ouverte pluridisciplinaire HAL, est destinée au dépôt et à la diffusion de documents scientifiques de niveau recherche, publiés ou non, émanant des établissements d'enseignement et de recherche français ou étrangers, des laboratoires publics ou privés. 


\section{Comparison of existing chloride ingress models within concretes exposed to seawater}

Article in Materials and Structures · January 2016

DOI: $10.1617 / s 11527-016-0803-y$

CITATIONS

3

3 authors, including:
READS

19

\section{Sylvain Pradelle}

Ministère de la Transition écologique et solid...

7 PUBLICATIONS 3 CITATIONS

SEE PROFILE

\section{Mickaël Thiery}

Ministère de la Transition Ecologique et Solid... 80 PUBLICATIONS 1,051 CITATIONS

SEE PROFILE 


\title{
Comparison of existing chloride ingress models within concretes exposed to seawater
}

\author{
Sylvain Pradelle · Mickaël Thiéry · Véronique \\ Baroghel-Bouny
}

Received: date / Accepted: date

\begin{abstract}
Numerous models to predict chloride ingress within concretes for different environmental conditions (immersed in seawater, located in the tidal zone or exposed to sea spray) have already been developed. Thanks to a benchmark, the objective of this paper is to contribute to the choice of a reliable engineering model for predicting chloride ingress in the case of saturated conditions. This study focus on a comparison between various physicochemical models which rely on different approaches to account for transport phenomena and binding of chloride ions onto the cementitious matrix. The authors draw special attention to models using a limited number of input data ( 3 or 4$)$ : accessible-to-water porosity $\left(\phi_{w}\right)$, effective chloride diffusion coefficient $\left(D_{\mathrm{Cl}^{-}}\right)$and one or two parameter(s) characterizing the physical binding of ions $\mathrm{Cl}^{-}$. They are determined through the analysis of two simple and repeatable experimental tests: $\phi_{w}$ is measured directly by hydrostatic weighing and the other parameters are fitted by inverse analysis performed of a total chloride content (tcc) profile at a given exposure time. An application of the method and a comprehensive comparison between predicted chloride profiles and experimental data (tcc profiles at other ages than the one used for the fitting and free chloride concentration (fcc) profiles) have been carried out for two mortars and seven concretes exposed to laboratory or in-situ conditions. The performance of the studied models is assessed thanks to statistical tools and recommendations are pointed out for the development of new numerical models.
\end{abstract}

Keywords Concrete $\cdot$ Chloride ingress $\cdot$ Modeling $\cdot$ Statistical $\cdot$ Comparisons

\section{Introduction}

Reinforced concrete (RC) structures are subjected to environment-induced corrosion that can lead to shortening their service life. Thus, it is necessary to optimize their design and

Sylvain Pradelle $(\bowtie) \cdot$ Mickaël Thiéry · Véronique Baroghel-Bouny

Université Paris-Est, IFSTTAR, MAST/FM²D, 14-20 Boulevard Newton, Cité Descartes, Champs sur Marne, F-77447 Marne-La-Vallée Cédex 2, France

E-mail: sylvain.pradelle@ifsttar.fr

Mickaël Thiéry

DGAC/STAC, Département Infrastructures Aéroportuaires, 31, avenue du Maréchal Leclerc, F-94381 Bonneuil-sur-Marne Cédex, France 
maintenance in order to minimize the costs. Standards $[4,1]$ propose a design method based on prescriptions in term of water-to-cement ratio and amounts of cement and supplementary cementitious materials. In order to have a more suitable design approach, recommendations, based on performances to be achieved in term of durability properties are proposed in literature $[5,10,14]$. By joining this latter idea, methods suitable for engineers are generally needed to determine the durability of RC structures against environmental attack related to rebars corrosion. This implies in particular the development of robust modeling tools for predicting chloride ingress and a collection of input data which should not mobilize complex and expensive measurements. Moreover, the developed methodology must keep a physical and chemical basis to reach enough flexibility and be handy. Indeed, in contrast to empirical laws, these models limit the number of necessary input data which have to be experimentally assessed (directly or by calibration). These input data have a physical and/or a chemical meaning, which facilitates the understanding of phenomena.

The objective of this paper is to contribute to the choice of reliable engineering models for predicting chloride ingress within concrete. The authors propose a comprehensive benchmark study between different physico-chemical models. They consider two main limitations for the set of tools. Firstly, only models centered on the point of view of cementitious materials are taken into account with no focus on the description of corrosion of rebars. Secondly, numerical modeling tools developed for fully saturated conditions are compared for their simplicity of use and due to the numerous experimental data available in the literature for such conditions.

In this context, previous benchmarks $[24,38]$ have already been done on a limited number of cementitious materials, but without evaluating the relevance of numerical predictions at various exposure times. A more detailed comparison (more materials and available chloride profiles at different exposure times) need to be thus held.

In fully saturated conditions, ion ingress within cementitious materials is ruled by a diffusion mechanism slowed by interactions of ions with the solid matrix. Diffusion is influenced by the geometrical properties of the porous network. It is generally described using four main characteristics: tortuosity, porosity, connectivity and even pore size distribution for transport in the smaller pores of the gel microstructure (cf. Knudsen effects). Moreover, electro-chemical interactions between all the present ionic species exist and can influence the diffusion process.

The interactions of chloride with the solid matrix cannot be neglected [26,28]. Two kinds of binding can be distinguished: chemical and physical ones. Firstly, chemical chloride binding is assumed to result from the formation of Friedel's salt $\left(\mathrm{C}_{3} \mathrm{~A} \cdot \mathrm{CaCl}_{2} \cdot 10 \mathrm{H}_{2} \mathrm{O}\right)$ and other analogue salts. Two mechanisms has been proposed in the literature: chloride ions react with the non-hydrated tricalcium aluminate $\left(C_{3} A\right)$ and the non-hydrated tetracalcium alumino-ferrite $\left(C_{4} A F\right)[22,33]$ and/or an ionic exchange process between chloride and sulfate ions occurs in the hydrated sulfo-aluminate phases $(A F m / A F t)[7,22,37]$. Secondly, a significant part of the interactions correspond to a physical adsorption onto the solid matrix, in particular, onto the calcium silicate hydrates $(C-S-H)$ [41] and the $A F m$ / AFt phases [37]. For ordinary Portland cement (OPC) systems, Tang and Nilsson [41] demonstrate that chloride binding is mainly governed by physical adsorption onto $C-S-H$. Ramachandran [33] details three forms of interaction with $C-S-H$ : chemical sorption, capture in the $C-S-H$ interlayer spaces and intimately binding in the $C-S-H$ lattice.

In addition to the chloride binding issue, the complexity of the ionic composition of the seawater and the pore solution of concretes suggest that a competitive binding of ions on the solid matrix may occur. Indeed, experimental results published by Suryavanshi [37] and 


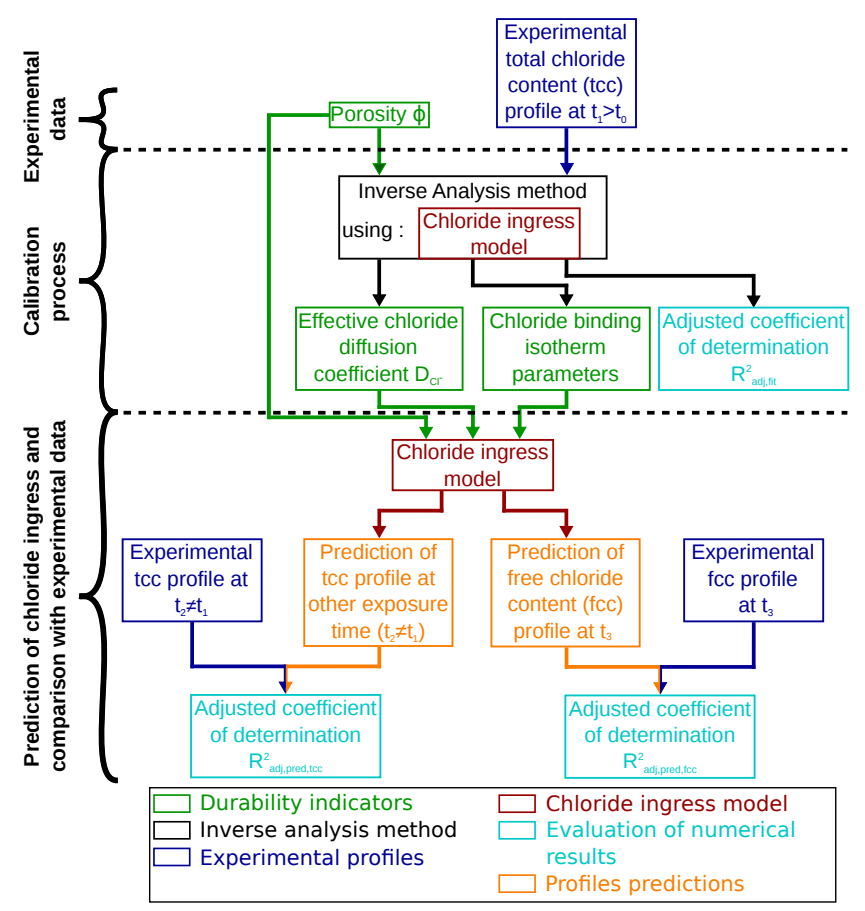

Fig. 1 Synthesis of the developed methodology for calibration of chloride ingress models and prediction of chloride profiles.

Tritthart [42] show a competition of adsorption onto $C$ - $S$ - $H$ between chloride and hydroxide ions. In the same way, Kari et al. [23] consider competition effects including several ions.

Another important phenomena to be taken into account for modeling is the dissolutionprecipitation reactions of the different compounds of the solid matrix (portlandite denoted $\mathrm{CH}, \mathrm{AFm} / \mathrm{AFt}$ phases, etc.). These reactions are introduced in the predicting models based on geochemical approaches $[8,21,23,32]$. As these models are not easy-to-use from an engineer point of view (many input data, difficult numerical implementation, etc.), they are excluded from the framework of this study. Nevertheless, the buffer role of $\mathrm{CH}$ through its dissolution is considered as particularly important given the crucial role of this hydration product to control the $p \mathrm{H}$ value of the pore solution (for instance in seawater conditions, if $\mathrm{CH}$ is not taken into account, the calculated $\mathrm{pH}$ can be unrelevant and even turn below 5!).

A schematic representation of the developed methodology used in the present article for the benchmark of models is given in Fig. 1. The studied models use three or four input data: porosity $(\phi)$, effective chloride diffusion coefficient $\left(D_{C l^{-}}\right)$and one or two parameters related to the chloride binding description (Chloride Binding Isotherm, CBI). Available experimental data from seven concretes and two mortars are analyzed to assess them: accessible-to-water porosity to assess $\phi_{w}$ and one total chloride content (tcc) profile at a given age of exposure to assess $D_{\mathrm{Cl}^{-}}$and one or two parameters of CBI. To evaluate if the calibrated parameters are physically acceptable, the adjusted coefficient of determination $\left(R_{a d j}^{2}\right)$ is calculated. After calibration, the adjusted model is used to predict tcc profiles for other available exposure times, in particular at other ages than the one used for the fitting, and fcc profiles (if they are available). The discrepancy between numerical predictions and 
experimental profiles is again estimated using $R_{a d j}^{2}$. Thus, the performance of studied models to predict chloride ingress is evaluated and a discriminating ranking can be proposed.

The present paper is decomposed as follows. Firstly, the studied physico-chemical chloride ingress models are described. Secondly, the developed methodology is precised: numerical resolution strategy, calibration process and selected statistical indicator. Then, the performance of the studied models is assessed by ensuring the success of the calibration process (chloride profiles, $D_{\mathrm{Cl}^{-}}$and CBIs parameters physically acceptable) and by comparing predictive results to experimental data. To conclude, main features and recommendations are pointed out for the development of numerical predictive chloride ingress models in saturated conditions.

\section{Description of the considered studied physico-chemical chloride ingress models}

Several previous studies have introduced different models predicting chloride ingress into saturated cementitious materials. Different degrees of refinement exist:

- Simple diffusion of chloride ions slowed down by its binding on the solid matrix [18, 39];

- Multi-diffusion of a restricted number of ions only coupled with chloride binding [28, 44];

- Multi-diffusion of a large number of ions only coupled with complex binding phenomena $[21,23,25]$.

This paper focuses on one-dimensional, physico-chemical and engineering-friendly models since they are also consistent with the framework of the French performance-based approach for concrete durability [10] with limited input data (three or four). Three physical and chemical phenomena are taken into account and described in the following sections: ion transport within the concrete, ion binding onto the solid matrix, and dissolution-precipitation reaction of $\mathrm{CH}$. Maximum eight ionic species are considered here: chloride $\left(\mathrm{Cl}^{-}\right)$, sodium $\left(\mathrm{Na}^{+}\right)$, potassium $\left(\mathrm{K}^{+}\right)$, calcium $\left(\mathrm{Ca}^{2+}\right)$, magnesium $\left(\mathrm{Mg}^{2+}\right)$, sulfate $\left(\mathrm{SO}_{4}^{2-}\right)$, hydroxyl $\left(\mathrm{OH}^{-}\right)$and hydron $\left(H^{+}\right)$ions. They correspond to the principal ionic species present in seawater and in the concrete interstitial solution.

\subsection{Transport description}

Different levels of refinement are available to describe ion transport. A simple description of ion transport considers only chloride ions and their movement caused by the gradient of concentration, through the Fick law. A more relevant and comprehensive approach consists in a multispecies transport model. It takes into account the diffusion of all considered ionic species and the electrical interactions between them. Such an approach can be modeled by the simplified Nernst-Planck equation $[28,44]$ :

$$
J_{i}=-D_{i}\left[\frac{\partial c_{i}}{\partial x}+\frac{c_{i} z_{i} F}{R T} \frac{\partial \psi}{\partial x}\right]
$$

where $J_{i}, D_{i}, c_{i}$ and $z_{i}$ are the molar flux $\left(\mathrm{mol} . \mathrm{m}^{-2} \cdot \mathrm{s}^{-1}\right)$, the effective diffusion coefficient $\left(\mathrm{m}^{2} \cdot \mathrm{s}^{-1}\right)$, the concentration $\left(\mathrm{mol} \cdot \mathrm{m}^{-3}\right)$, the valence number $(-)$ associated with each ion $i$, respectively. $\psi$ is the local electrical potential (V) which arises in order to maintain electroneutrality in the pore solution. $F$ is the Faraday constant $\left(96485.3328959\right.$ C.mol $\left.{ }^{-1}\right), R$ the 
ideal gas constant $\left(8,3144621 \mathrm{~J} \cdot \mathrm{mol}^{-1} \cdot \mathrm{K}^{-1}\right), T$ the absolute temperature $(\mathrm{K})$, and $x$ the depth (m).

The effective diffusion coefficient of each involved species is determined by using a theoretical definition which is commonly used in the literature $[28,36]$ :

$$
D_{i}=\tau \phi D_{i}^{0}
$$

where $\tau, \phi$ and $D_{i}^{0}$ are the tortuosity, the porosity and the intrinsic diffusion coefficient in water related to species $i$, respectively. Stating that the values of porosity and tortuosity are independent of the type of ion, all the effective diffusion coefficients are proportional to each other. Thus, the effective diffusion coefficient related to chloride is sufficient to determine the others.

\subsection{Binding description}

For a given specie $i$, Eq. 3 distinguishes the free ions in solution from the ions bound onto the cementitious matrix:

$$
n_{i}=\phi c_{i}+s_{i}
$$

where $n_{i}$ and $s_{i}$ are the molar content of the ionic species $i$ (mol.m ${ }^{-3}$ of concrete) and the amount of the ionic species $i$ bound onto the cementitious matrix (mol. $\mathrm{m}^{-3}$ of concrete), respectively.

Previous studies $[44,46]$ have underlined that the kinetics of binding of ions is faster than the diffusion process. Thus, considering an equilibrium between free ions in the interstitial solution and ions bound onto the cementitious matrix is an acceptable assumption. The content of the bound ion $i$ is easily described as a function of the concentrations of free ions presented in the interstitial solution.

In the remainder of this paper, the adopted description for the interactions ion/solid matrix is based on previously proposed theories of physical adsorption onto solid surfaces (mainly onto $C-S-H$ ). However, the chemical binding of chloride ions cannot be neglected since the amounts of $C_{3} A$ (see Tab. 4) in the cements used in the present study are higher than $7 \%$ of the clinker mass. In the absence of description suitable for engineers, no equation consider explicitly the chemical binding. As the binding description is calibrated by inverse analysis on tcc profiles (see Sec. 3.2), chemical and physical binding will be taken into account whatever equations the authors choose. Three different approaches will be developed in this paper to quantify chloride binding.

Firstly, a simple description is based on chloride ion binding. In this paper, the authors deal with three classical chloride binding isotherms (see Tab. 1): linear, Freundlich (empirical) and Langmuir (one layer adsorption theory) isotherms. For these three isotherms, one or two parameters must be calibrated.

Secondly, a more comprehensive description considers a competitive adsorption onto the solid matrix between chloride and hydroxide ions. This is in agreement with experimental results found by Suryavanshi [37] and Tritthart [42]. Consequently, an isotherm based on the double layer (DL) theory $[6,47]$ is defined in Eq. 7 :

$$
\left\{\begin{array}{l}
s_{\mathrm{Cl}}=f_{\mathrm{DL}}^{\mathrm{Cl}}\left(c_{\mathrm{Cl}^{-}}, c_{\mathrm{OH}^{-}}\right)=\frac{\alpha^{\prime} c_{\mathrm{Cl}}}{{ }_{\mathrm{OH}^{-}+\beta^{\prime} c_{\mathrm{Cl}^{-}}}} \\
s_{\mathrm{OH}}=f_{D L}^{O H}\left(c_{\mathrm{Cl}^{-}}, c_{\mathrm{OH}^{-}}\right)=\frac{\alpha^{\prime} c_{\mathrm{OH}^{-}}}{\beta^{\prime}\left(c_{\mathrm{OH}^{-}}+\beta^{\prime} c_{C l^{-}}\right)}
\end{array}\right.
$$


Table 1 Equations of three classical chloride binding isotherms: the linear, the Freundlich and the Langmuir isotherms. The parameters $K,(\mu, \gamma)$ and $(\alpha, \beta)$ describe the adsorption capacity of $C-S-H$ and they must be calibrated.

\begin{tabular}{|c|c|c|}
\hline CBI name & Equations & Parameters \\
\hline Linear & $s_{C l}=f_{L i}\left(c_{C l^{-}}\right)=K c_{C l^{-}} \quad(4)$ & $K>0$ \\
\hline Freundlich & $s_{C l}=f_{F r}\left(c_{C l^{-}}\right)=\mu c_{C l^{-}}^{\gamma} \quad(5)$ & $\mu>0,0<\gamma<1$ \\
\hline Langmuir & $s_{C l}=f_{L a}\left(c_{C l^{-}}\right)=\frac{\alpha c_{C l^{-}}}{1+\beta c_{C l^{-}}}(6)$ & $\alpha>0, \beta>0$ \\
\hline
\end{tabular}

where the parameters $\left(\alpha^{\prime}, \beta^{\prime}\right)$ have to be calibrated. They depend on the amount of hydrates on which ions $\mathrm{Cl}^{-}$can be adsorbed and their intrinsic properties like their specific surface area. Note that, with this model, the $p \mathrm{H}$ of the interstitial solution has an influence on chloride adsorption. Nonetheless, if the $p \mathrm{H}$ value is unknown, a standard value equal to 13.5 is generally considered as it is globally representative of the $p \mathrm{H}$ value of the pore solution in concretes.

Lastly, some authors consider a multispecies competition of adsorption onto $C-S-H$ and thus binding of several ionic species. Tab. 7 resumes such adsorption reactions proposed by Kari et al. [23]. This theoretical framework is copied and then applied to the whole solid matrix able to adsorb ions. Analytical formula (see Appendix A) are deduced from these reactions considered at equilibrium in order to link the content of bound ions to the concentration of free ions. In our framework, the content of bound ions depends on two types of parameters: $C_{a d s}$ representing the unknown potential of concrete to adsorb ions onto its solid matrix (to be fitted) and known equilibrium constants of adsorption (see Tab. 7) associated with the adsorption reactions onto $C-S-H$.

For each analytical formula, one parameter (linear isotherm and multispecies adsorption onto solid matrix) or two parameters (Freundlich, Langmuir and DL isotherms) is assessed on the basis of inverse analysis of an experimental tcc profile. The method of calibration is presented in section 3.2.

\subsection{Buffer role of portlandite}

The authors propose a first level of description of the role of dissolution-precipitation reactions. This description is not exhaustive but it takes into account the equilibrium of $\mathrm{CH}$ with the interstitial solution. Thus, its buffer role [45] is considered. For this purpose, an hypothesis is made in order to have a lightweight modeling: the content of $\mathrm{CH}$ is considered high enough to ensure at any time and anywhere its equilibrium with the pore solution (see Eq. 8):

$$
\mathrm{Ca}(\mathrm{OH})_{2} \Leftrightarrow \mathrm{Ca}^{2+}+2 \mathrm{OH}^{-} \mathrm{K}_{\mathrm{p}}=c_{\mathrm{Ca}^{2+}} \mathrm{C}_{\mathrm{OH}^{-}}^{2}=10^{-5.2}
$$




\section{Methodology}

This section aims to present the strategy used for the benchmark: resolution strategy, inverse analysis methodology, and statistical indicators to assess the performance of the fitting and the prediction.

3.1 Balance equations and numerical resolution strategy

Chloride ingress within saturated cementitious materials is solved in the framework of a mass conservative problem. Thus, for each ionic species $i$, a mass balance equation is written as follows:

$$
\frac{\partial n_{i}}{\partial t}=-\nabla \cdot \mathbf{J}_{\mathbf{i}}
$$

where $t$ is the time (s).

The strategy of resolution of the equations systems is synthesized in Tab. 2: the considered equations, their numbers, the input data and the unknown variables are specified. Three levels of modeling are identified:

- Mono-ionic models (MI1);

- Multispecies models considering five ions (MS5);

- Multispecies models considering eight ions (MS8).

Considering MI1 models, the simplest description of chloride ingress takes into account its diffusion coupled with a linear CBI. The authors use an analytical law based on the error function to solve this configuration of modeling, adding the hypothesis that transfers occur through a semi-infinite medium. When a non linear CBI is coupled with a mono-ionic transport model, no analytical solution can be proposed and a numerical resolution of the mass balance equation of chloride ions is required.

In MS5 models, a more comprehensive approach takes into account other present ions than chloride ions in the interstitial solution. Baroghel-Bouny et al. [12] consider five ionic species: chloride, sodium, potassium, hydroxide and hydron ions. Various non linear isotherms for chloride (Freundlich, Langmuir and DL isotherms) can be used (see Tab. 1 and Eq. 7). Mass balance equations for the ions $\mathrm{Cl}^{-}, \mathrm{Na}^{+}$and $\mathrm{K}^{+}$are considered. $\mathrm{OH}^{-}$and $\mathrm{H}^{+}$concentrations are determined using the electro-neutrality condition and the self-ionization equation of water. This implies the resolution of a polynomial of degree two in which $\mathrm{COH}^{-}$is the unknown variable. The electrical potential $\psi$ is set by using a balance equation of electrical charge.

In MS8 models, three new ions are added to the five ions previously considered: magnesium, calcium and sulphate ions. A similar resolution strategy as for models MS5 is considered: the mass balance equations of the ions $\mathrm{Cl}^{-}, \mathrm{Na}^{+}, \mathrm{K}^{+}, \mathrm{Mg}^{2+}$ and $\mathrm{SO}_{4}^{2-}$ are solved and the $\mathrm{Ca}^{2+}, \mathrm{OH}^{-}$and $\mathrm{H}^{+}$concentrations are determined by considering the electro-neutrality condition coupled with the equilibrium of the dissolution-precipitation reaction of $\mathrm{CH}$ and the self-ionization of water. In this case, this implies the resolution of a polynomial of degree three in which the unknown variable is $c_{\mathrm{OH}^{-}}$.

Except for the simplest description (level 1 with a linear CBI), equations are solved by a finite-volume code named Bil in C language [12,13,28]. For a synthetic overview, Tab. 3 summarizes the eight physico-chemical models studied in this paper. 
Table 2 Numerical strategy of resolution of the equations systems. The index $i$ browses 3 ions: $\mathrm{Cl}^{-}, \mathrm{Na}^{+}$ and $\mathrm{K}^{+}$. The index $\alpha$ ranges 5 ions: $\mathrm{Cl}^{-}, \mathrm{Na}^{+}, \mathrm{K}^{+}, \mathrm{OH}^{-}$and $\mathrm{H}^{+}$. The index $\mathrm{j}$ browses 5 ions: $\mathrm{Cl}^{-}, \mathrm{Na}^{+}$, $\mathrm{K}^{+}, \mathrm{Mg}^{2+}$ and $\mathrm{SO}_{4}^{2-}$. The index $\beta$ ranges 8 ions: $\mathrm{Cl}^{-}, \mathrm{Na}^{+}, \mathrm{K}^{+}, \mathrm{OH}^{-}, \mathrm{H}^{+}, \mathrm{Ca}^{2+}, \mathrm{Mg}^{2+}$ and $\mathrm{SO}_{4}^{2-}$. The index $k$ browses 6 ions: $\mathrm{Cl}^{-}, \mathrm{Na}^{+}, \mathrm{K}^{+}, \mathrm{OH}^{-}, \mathrm{Ca}^{2+}$, and $\mathrm{SO}_{4}^{2-}$. The explicitly solved unknown variables are underlined.

\begin{tabular}{|c|c|c|c|c|}
\hline Models & Equations & $\begin{array}{c}\text { Number } \\
\text { of equations }\end{array}$ & $\begin{array}{l}\text { Input } \\
\text { data }\end{array}$ & $\begin{array}{l}\text { Unknow } \\
\text { variables }\end{array}$ \\
\hline \multirow{3}{*}{$\begin{array}{l}\text { Mono-ionic } \\
\text { (MI1) }\end{array}$} & $\frac{\partial\left(\phi c_{C l^{-}}+s_{C l}\right)}{\partial t}=-D_{C l^{-}} \frac{\partial c_{C l^{-}}}{\partial x}$ & 1 & $\phi, D_{C l^{-}}$ & \multirow[b]{2}{*}{$\underline{c_{C l^{-}},} s_{C l}$} \\
\hline & $\begin{array}{c}s_{C l}=f_{L i}\left(c_{C l^{-}}\right) \text {or } s_{C l}=s_{C l}=f_{F r}\left(c_{C l^{-}}\right) \\
\text {or } s_{C l}=f_{L a}\left(c_{C l^{-}}\right) \text {or } s_{C l}=f_{D L}^{C l}\left(c_{C l^{-}}, c_{\mathrm{OH}^{-}}\right)\end{array}$ & 1 & $\begin{array}{l}\text { Parameters } \\
\text { of CBI }\end{array}$ & \\
\hline & Total & 2 & Total & 2 \\
\hline \multirow{6}{*}{$\begin{array}{l}\text { Multispecies } \\
5 \text { ions (MS5) }\end{array}$} & $\frac{\partial\left(\phi c_{i}+s_{i}\right)}{\partial t}=-D_{i}\left[\frac{\partial c_{i}}{\partial x}+\frac{c_{i} z_{i} F}{R T} \frac{\partial \psi}{\partial x}\right]$ & 3 & $\phi, D_{C l^{-}}$ & \multirow{3}{*}{$\begin{array}{l}\underline{c_{C l^{-}},} s_{C l} \\
\underline{c_{N a^{+}},}, \underline{c_{K^{+}}}\end{array}$} \\
\hline & $\frac{\partial\left(F \sum_{\alpha} z_{\alpha} J_{\alpha}\right)}{\partial x}=0$ & 1 & - & \\
\hline & $c_{\mathrm{OH}^{-}}{ }^{2}+\left(c_{\mathrm{Na}^{+}}+c_{K^{+}}-c_{\mathrm{Cl}^{-}}\right) c_{\mathrm{OH}^{-}}+K_{e}=0$ & 1 & - & \\
\hline & $c_{\mathrm{OH}^{-}} c_{H^{+}}=K_{e} \quad p K_{e}=14$ & 1 & - & \multirow{2}{*}{$\begin{array}{c}c_{\mathrm{OH}^{-}}, c_{H^{+}} \\
\text {and } \underline{\psi}\end{array}$} \\
\hline & $\begin{array}{c}s_{C l}=f_{F r}\left(c_{C l^{-}}\right) \text {or } s_{C l}=f_{L a}\left(c_{C l^{-}}\right) \\
\text {or } s_{C l}=f_{D L}^{C l}\left(c_{C l^{-}}, c_{\mathrm{OH}^{-}}\right)\end{array}$ & 1 & $\begin{array}{l}\text { Parameters } \\
\text { of CBI }\end{array}$ & \\
\hline & Total & 7 & Total & 7 \\
\hline \multirow{7}{*}{$\begin{array}{l}\text { Multispecies } \\
8 \text { ions (MS8) }\end{array}$} & $\frac{\partial\left(\phi c_{j}+s_{j}\right)}{\partial t}=-D_{j}\left[\frac{\partial c_{j}}{\partial x}+\frac{c_{j} z_{j} F}{R T} \frac{\partial \psi}{\partial x}\right]$ & 5 & $\phi, D_{C l^{-}}$ & \multirow{4}{*}{$\begin{array}{c}\underline{c_{C l^{-}},} s_{C l}, \\
\frac{c_{N a^{+}},}{c_{K^{+}}}, s_{K a}, \\
\frac{c_{O H^{-}},}{c_{\mathrm{OH}},} \\
c_{\mathrm{SO}_{4}^{2-}}, s_{\mathrm{SO}_{4}^{2-}},\end{array}$} \\
\hline & $\frac{\partial\left(F \sum_{\beta} z_{\beta} J_{\beta}\right)}{\partial x}=0$ & 1 & - & \\
\hline & $\begin{array}{c}\left(c_{\mathrm{Na}^{+}}+c_{\mathrm{K}^{+}}+2 c_{\mathrm{Mg}^{2+}}-c_{\mathrm{Cl}^{-}}-2 c_{\mathrm{SO}_{4}^{2-}}\right) c_{\mathrm{OH}^{-}}{ }^{2} \\
-c_{\mathrm{OH}^{-}}{ }^{3}+K_{e} c_{\mathrm{OH}^{-}}+K_{p}=0\end{array}$ & 1 & - & \\
\hline & $c_{O H^{-}} c_{H^{+}}=K_{e} \quad p K_{e}=14$ & 1 & - & \\
\hline & $\left(c_{\mathrm{OH}^{-}}\right)^{2} c_{\mathrm{Ca}^{2+}}=K_{p} \quad p K_{p}=5.2$ & 1 & - & $\underline{c_{M g^{2}+}}, c_{H^{+}}$ \\
\hline & $s_{k}=f_{\mathrm{Kari}}^{k}\left(c_{\mathrm{Cl}^{-}}, c_{\mathrm{OH}^{-}}, c_{\mathrm{SO}_{4}^{2-}}, c_{\mathrm{Na}^{+}}, c_{\mathrm{K}^{+}}, c_{\mathrm{Ca}^{2+}}\right)$ & 6 & $\begin{array}{l}\text { Parameters } \\
\text { of CBI }\end{array}$ & $\begin{array}{c}c_{C a^{2+}}, s_{C a} \\
\text { and } \underline{\psi}\end{array}$ \\
\hline & Total & 15 & Total & 15 \\
\hline
\end{tabular}

Table 3 Synthesis of physico-chemical studied models.

\begin{tabular}{|c|c|c|c|c|c|c|c|c|c|c|}
\hline \multirow{2}{*}{ 递 } & \multirow{2}{*}{ Models } & \multicolumn{7}{|c|}{ Species } & \multirow{2}{*}{$\begin{array}{c}\text { Adsorption } \\
\text { on } C-S-H\end{array}$} & \multirow{2}{*}{$\begin{array}{c}\text { Buffer } \\
\text { role } \\
\text { of } C H\end{array}$} \\
\hline & & $\mathrm{Cl}^{-}$ & $\mathrm{Na}^{+}$ & $K^{+}$ & $\mathrm{OH}^{-}$ & $H^{+}$ & $\mathrm{Ca}^{2+}$ & $\mathrm{Mg}^{2+} \quad \mathrm{SO}_{4}^{2-}$ & & \\
\hline \multirow{4}{*}{1} & Erf & $\sqrt{ }$ & & & & & & & Linear & \\
\hline & MI1_Fre & $\sqrt{ }$ & & & & & & & Freundlich & \\
\hline & MI1_Lang & $\sqrt{ }$ & & & & & & & Langmuir & \\
\hline & MI1_DL $^{a}$ & $\sqrt{ }$ & & & & & & & DL & \\
\hline \multirow{3}{*}{2} & MS5_Fre & $\sqrt{ }$ & $\sqrt{ }$ & $\sqrt{ }$ & $\checkmark$ & $\checkmark$ & & & Freundlich & \\
\hline & MS5_Lang & $\sqrt{ }$ & $\sqrt{ }$ & $\sqrt{ }$ & $\checkmark$ & $\sqrt{ }$ & & & Langmuir & \\
\hline & MS5_DL & $\sqrt{ }$ & $\sqrt{ }$ & $\sqrt{ }$ & $\checkmark$ & $\sqrt{ }$ & & & $\mathrm{DL}$ & \\
\hline 3 & MS8_K_act & $\sqrt{ }$ & $\sqrt{ }$ & $\sqrt{ }$ & $\sqrt{ }$ & $\sqrt{ }$ & $\sqrt{ }$ & $\sqrt{ }$ & Kari & $\sqrt{ }$ \\
\hline
\end{tabular}

${ }^{a}$ For this model, the $p \mathrm{H}$ is considered equal to 13.5 in the interstitial solution in order to define the DL isotherm. 
3.2 Numerical calibration method and verification of predictions

\subsubsection{Definition of the adjusted coefficient of determination}

The adjusted coefficient of determination $R_{a d j}^{2}$ is used to assess the accuracy of simulated profiles with experimental data. It is defined as:

$$
\begin{aligned}
R_{a d j}^{2}=\frac{(n-1) R^{2}-(m-1)}{(n-m)} & \left(R^{2}=1-\frac{\sum_{i=1}^{n}\left(Z_{C l_{i}^{m s}}-Z_{C l}^{p r}\right)^{2}}{\sum_{i=1}^{n}\left(Z_{C l i}^{m s}\right)^{2}}\right)
\end{aligned}
$$

where $m$ and $n$ are the number of parameters to be fitted and the number of available experimental data, respectively. $Z_{C l}{ }_{i}^{m s}$ and $Z_{C l}{ }_{i} r$ represent the amounts of chloride (total content or free concentration) experimentally measured and numerically calculated, respectively.

The coefficient of determination $R^{2}$ evaluates the existing difference between the experimental data and the corresponding numerical profile. $R_{a d j}^{2}$ is an extension of $R^{2}$ as it considers the numbers of measured data and parameters which have to be fitted. $R_{a d j}^{2}$ takes into account the fact that the use of more parameters can yield a higher $R^{2}$ value, but a lower robustness and a lower sensitivity to parameters as well.

$R_{a d j}^{2}$ results can be analyzed as follows. Firstly, if $R_{a d j}^{2}$ is close to 1, it indicates a satisfactory result. Nevertheless, it remains difficult to indicate an a priori threshold values for this statistical indicator. That is why practical verifications between experimental and numerical chloride profiles have to be carried out in parallel in order to ensure the relevance of the simulation. Secondly, when one model is considered, the dispersion of $R_{a d j}^{2}$ values gathered for all studied concretes indicates the repeatability of the methodology. Thus, for each model, the objective is to find a standard deviation of $R_{a d j}^{2}$ closest as possible to 0 .

\subsubsection{Calibration process and assessment of prediction quality}

For the assessment of $D_{C l^{-}}$and CBI parameters (1 or 2), the calibration method is based on a non linear least squared optimization procedure performed on an experimental tcc profile at a given age. A numerical algorithm based on the downhill simplex method [27] is used in order to find the unknown parameters that minimize the sum of squared errors between experimental data and numerical profile. As this algorithm corresponds to an iterative method, different starting points are selected in order to cover the usual range of values for $D_{\mathrm{Cl}^{-}}$and CBI parameters. The couple ( $D_{\mathrm{Cl}^{-}}, \mathrm{CBI}$ parameters) giving the best result according to $R_{a d j}^{2}$ is chosen. The quality of the calibration is visually checked by comparing numerical and experimental tcc profiles. The relevance of the fitted parameters and the shape of the CBI is also controlled.

After achieving calibration, chloride ingress models are used to predict tcc profiles at another age than the one used for the fitting and fcc profiles. The statistical tool $R_{a d j}^{2}$ is again used to evaluate the discrepancy between predicted profiles and experimental data.

\subsection{Studied materials}

Concretes ranging from low-grade to high-performance materials are studied (see Tab. 4). Some materials take part of the French project BHP 2000 [17] (concretes M25, M30FA, 
Table 4 Main characteristics of the studied concretes [12,24,29].

\begin{tabular}{|c|c|c|c|c|c|c|c|c|c|c|c|}
\hline \multirow{2}{*}{\multicolumn{3}{|c|}{ Concretes // Mortars }} & Labor & ory & & & & & In-situ & & \\
\hline & & & M25 & BO & M30FA & C1 & Mo1 & Mo2 & M75SF & M120SF & $\mathbf{H 4}$ \\
\hline \multicolumn{3}{|c|}{$\begin{array}{l}\text { Gravel }(\mathrm{G}) \text { content }\left(\mathrm{kg} \cdot \mathrm{m}^{-3}\right) \\
(\mathrm{min} / \mathrm{max} \text { grain size }(\mathrm{mm}))\end{array}$} & $\begin{array}{l}1007 \\
(5 / 20)\end{array}$ & $\begin{array}{l}1192 \\
(4 / 20)\end{array}$ & $\begin{array}{l}986 \\
(4 / 20)\end{array}$ & $\begin{array}{l}825 \\
(3 / 8)\end{array}$ & - & $\begin{array}{l}- \\
-\end{array}$ & $\begin{array}{l}1044 \\
(5 / 20)\end{array}$ & $\begin{array}{l}991 \\
(5 / 20)\end{array}$ & $\begin{array}{l}842.5 \\
(8 / 16)\end{array}$ \\
\hline \multirow{2}{*}{\multicolumn{3}{|c|}{$\begin{array}{l}\text { Sand }(\mathrm{S}) \text { content }\left(\mathrm{kg} \cdot \mathrm{m}^{-3}\right) \\
(\mathrm{min} / \mathrm{max} \text { grain size }(\mathrm{mm}))\end{array}$}} & 899 & 744 & 879 & 695 & 1365 & 1253 & 877 & 820 & 842.5 \\
\hline & & & $(0 / 5)$ & $(0 / 5)$ & $(0 / 5)$ & $(0 / 4)$ & $(0 / 4)$ & $(0 / 4)$ & $(0 / 5)$ & $(0 / 5)$ & $(0 / 8)$ \\
\hline \multicolumn{3}{|c|}{ Cement $(\mathrm{C})$ content $\left(\mathrm{kg} \cdot \mathrm{m}^{-3}\right)$} & 230 & 353 & 223 & 560 & 618 & $682^{a}$ & 360 & 470 & 399 \\
\hline \multicolumn{3}{|c|}{ Fly ash (FA) content $\left(\mathrm{kg} \cdot \mathrm{m}^{-3}\right)$} & 0 & 0 & 95 & 0 & 0 & 0 & 0 & 0 & 0 \\
\hline \multicolumn{3}{|c|}{ Silica fume (SF) content $\left(\mathrm{kg} \cdot \mathrm{m}^{-3}\right)$} & 0 & 0 & 0 & 0 & 0 & 0 & 22 & 57 & 21 \\
\hline \multicolumn{3}{|c|}{ Water $(\mathrm{W})$ content $\left(\mathrm{kg} \cdot \mathrm{m}^{-3}\right)$} & 193 & 172 & 166 & 224 & 264 & 267 & 136 & 124 & 168 \\
\hline \multicolumn{3}{|c|}{ Super-plasticisers (SP) content $\left(\mathrm{kg} \cdot \mathrm{m}^{-3}\right)$} & 0 & 0 & 1.1 & 0 & 7.72 & 10.22 & 12 & 15.6 & 3.4 \\
\hline \multicolumn{3}{|c|}{ Retarder $(\mathrm{R})$ content $\left(\mathrm{kg} \cdot \mathrm{m}^{-3}\right)$} & 0 & 0 & 1.4 & 0 & 0 & 0 & 2.5 & 3.3 & 0 \\
\hline \multirow{2}{*}{\multicolumn{3}{|c|}{$\begin{array}{l}C_{3} A \text { content ( } \% \text { by mass of clinker) } \\
C_{4} A F \text { content ( } \% \text { by mass of clinker) }\end{array}$}} & 2.5 & 4.3 & 2.5 & 6 & 10 & 2.8 & 2.5 & 2.5 & 1.3 \\
\hline & & & 14 & 6.9 & 14 & 8.5 & 9.6 & 12.2 & 14 & 14 & 14.3 \\
\hline \multirow{2}{*}{\multicolumn{3}{|c|}{$\begin{array}{l}\text { Water-to-binder ratio }(\mathrm{W} / \mathrm{B}) \\
\text { Average } 28 \text {-day cylinder } \\
\text { compressive strength }(\mathrm{MPa})\end{array}$}} & 0.84 & 0.49 & 0.52 & 0.40 & 0.43 & 0.39 & 0.36 & 0.23 & 0.40 \\
\hline & & & 22.2 & 58.6 & 48.5 & 49.5 & 76.1 & 70.7 & 85.5 & 127.5 & 63 \\
\hline \multicolumn{3}{|c|}{$\begin{array}{l}\text { Average porosity accessible } \\
\text { to water } \phi(-) \text { (age) }\end{array}$} & $\begin{array}{l}0.159 \\
(90 \mathrm{~d})\end{array}$ & $\begin{array}{l}0.124 \\
(90 \mathrm{~d})\end{array}$ & $\begin{array}{l}0.137 \\
(90 \mathrm{~d})\end{array}$ & $\begin{array}{l}0.159 \\
(28 \mathrm{~d})\end{array}$ & $\begin{array}{l}0.192 \\
(1 \mathrm{y})\end{array}$ & $\begin{array}{l}0.220 \\
(1 \mathrm{y})\end{array}$ & $\begin{array}{l}0.084 \\
(45 \mathrm{~d})\end{array}$ & $\begin{array}{l}0.074 \\
(45 \mathrm{~d})\end{array}$ & $\begin{array}{l}0.1169 \\
(217 d)\end{array}$ \\
\hline \multirow{6}{*}{$\begin{array}{l}0 \\
0 \\
0 \\
0 \\
0 \\
0 \\
0 \\
0 \\
0 \\
0\end{array}$} & & $\mathrm{Cl}^{-}$ & 0 & 0 & 0 & 1 & 0.5 & 2 & 0 & 0 & 0 \\
\hline & Initial concentration & $K^{+}$ & 0 & 0 & 0 & 156 & 272 & 362 & $\simeq 170^{b}$ & $\simeq 170^{b}$ & 255 \\
\hline & of the interstitial & $\mathrm{Na}^{+}$ & 100 & 100 & 100 & 23 & 100 & 94 & $\simeq 38^{b}$ & $\simeq 38^{b}$ & 34 \\
\hline & solution $\left(\mathrm{mol} . \mathrm{m}^{-3}\right)$ & $\mathrm{SO}_{4}^{2-}$ & 0 & 0 & 0 & $\simeq 1^{c}$ & $\simeq 1^{c}$ & $\simeq 4^{c}$ & $\simeq 1^{c}$ & $\simeq 1^{c}$ & $\simeq 1^{c}$ \\
\hline & & $M g^{2+}$ & 0 & 0 & 0 & $\simeq 0^{d}$ & $\simeq 0^{d}$ & $\simeq 0^{d}$ & $\simeq 0^{d}$ & $\simeq 0^{d}$ & $\simeq 0^{d}$ \\
\hline & \multicolumn{2}{|l|}{ Boundary condition } & \multicolumn{3}{|c|}{$\begin{array}{l}\text { Immersion } \\
\text { in } 30 \text { g.L } \mathrm{L}^{-1} \mathrm{NaCl} \\
+4 \text { g. } \mathrm{L}^{-1} \mathrm{NaOH}\end{array}$} & $\begin{array}{l}\text { Immersion } \\
\text { in } 33 \mathrm{~g} . \mathrm{L}^{-1} \\
\mathrm{NaCl}\end{array}$ & \multicolumn{2}{|c|}{$\begin{array}{l}\text { Immersion } \\
\text { in } 30 \text { g.L } \mathrm{L}^{-1} \mathrm{NaCl} \\
+2 \mathrm{~g} . \mathrm{L}^{-1} \mathrm{Ca}(\mathrm{OH})_{2}\end{array}$} & \multicolumn{2}{|c|}{$\begin{array}{l}\text { Tidal zone } \\
\text { (La Rochelle) } \\
\left(\text { seawater }^{e}\right)\end{array}$} & $\begin{array}{l}\text { Immersion } \\
\text { (Träslövsläge) } \\
\left(\text { seawater }^{f}\right)\end{array}$ \\
\hline
\end{tabular}

${ }^{a}$ The cement is composed of $55 \%$ of clinker, $22 \%$ of fly ash and $22 \%$ of ground-granulated blast-furnace slag.

${ }^{b}$ Experimental data are not available. Values for an high performance cement paste obtained by Baroghel-Bouny [9] are chosen.

${ }^{c}$ Values for ordinary and high performance (including silica fume) cement pastes obtained by Codina [16] are chosen.

${ }^{d}$ Because of a lack of available data, initial magnesium concentration is assumed to be equal to zero.

${ }^{e}$ In seawater (typical salinity equal to 35 g.L ${ }^{-1}$ ), the concentrations of $\mathrm{Cl}^{-}, \mathrm{Na}^{+}, \mathrm{K}^{+}, \mathrm{Mg}^{2+}$ and $\mathrm{Ca}^{2+}$ ions are equal to 19.7 g.L ${ }^{-1}, 11.1$ g.L ${ }^{-1}, 0.41$ g.L ${ }^{-1}$, $1.31 \mathrm{~g} . \mathrm{L}^{-1}$ and $0.42 \mathrm{~g} . \mathrm{L}^{-1}$, respectively.

$f$ Tang and Andersen [40] have achieved a seawater withdrawal and measured out a chloride ions concentration equal to 14 g.L ${ }^{-1}$. According to the Dittmar's law the relative proportions of the major chemical constituents of sea water are constant throughout all the oceans. Thus, the concentrations of $\mathrm{Na}^{+}, \mathrm{K}^{+}, \mathrm{Mg}^{2+}$ and $\mathrm{Ca}^{2+}$ ions are equal to 7.9 g.L $\mathrm{L}^{-1}, 0.29$ g.L ${ }^{-1}, 0.93$ g.L $\mathrm{L}^{-1}$ and 0.30 g.L $\mathrm{L}^{-1}$, respectively.

M75SF and M120SF). This set of concretes is completed by three other concretes (BO, $\mathrm{C} 1$ and H4) $[12,31,24]$ and two mortars (Mo1 and Mo2) [29]. The data for the concretes $\mathrm{C} 1, \mathrm{H} 4, \mathrm{Mo} 1$ and Mo2 are taken from other studies illustrated in the literature. Note that concrete H4, made with a sulfate-resistant Portland cement and silica fume, was studied in the European project Chlortest [38]. The authors class the studied cementitious materials according to two categories: laboratory (lab.) materials (M25, BO, M30FA, C1, Mo1 and Mo2) and in-situ materials (M75SF, M120SF and H4). Thiery2012 For the studied materials, $\phi_{w}$ is assessed by hydrostatic weighing according to the French Standard NF P18-459 [12, 13]. As discussed before, $D_{C l^{-}}$and CBI parameter(s) are calibrated by numerical inverse analysis of an available experimental tcc profile (see Tab. 5). These profiles were measured by a potentiometric titration after nitric acid extraction [15]. It is important to note that the number of experimental data available for concrete M120SF on the profiles at 2 and 4 years is insufficient to carry out inverse analysis. For this reason, data for these two ages will be brought together for the calibration. Three types of tcc profiles are used for the calibration depending either they are obtained in laboratory, or in-situ conditions: 
Table 5 Chloride profiles available for each concrete. Tcc profiles used for the inverse analysis are highlighted.

\begin{tabular}{|c|c|c|c|c|c|c|c|c|c|}
\hline \multirow{2}{*}{ Concretes // Mortars } & \multicolumn{6}{|c|}{ Laboratory } & \multicolumn{3}{|l|}{ In-situ } \\
\hline & M25 & BO & M30FA & C1 & Mo1 & Mo2 & M75SF & M120SF & $\overline{\mathrm{H} 4}$ \\
\hline $\begin{array}{l}\text { Tcc profiles used for } \\
\text { the inverse analysis }\end{array}$ & $90 \mathrm{~d}$ & $84 \mathrm{~d}$ & $90 \mathrm{~d}$ & $180 \mathrm{~d}$ & $6 \mathrm{~m}$ & $4 \mathrm{~m}$ & $2 y$ & $2-4 y$ & $1.047 \mathrm{y}$ \\
\hline $\begin{array}{l}\text { Other tcc profiles } \\
\text { available }\end{array}$ & $150 \mathrm{~d}$ & $210 \mathrm{~d}$ & - & - & - & $6 \mathrm{~m}$ & $4,10 \mathrm{y}$ & $10 \mathrm{y}$ & $2.027,5 y$ \\
\hline Fcc profiles available & $90,150 \mathrm{~d}$ & $84,210 d$ & $90 \mathrm{~d}$ & - & - & - & - & - & - \\
\hline
\end{tabular}

- For lab. conditions, concrete specimens are immersed in an alkaline solution with a $p \mathrm{H}$ close to 13;

- M75SF and M120SF specimens are placed in a tidal zone in La Rochelle, France (Atlantic Ocean) with a $p \mathrm{H}$ close to 8.2 and a salinity equal to $35 \mathrm{~g} . \mathrm{L}^{-1}$. The following assumption is made: as M75SF and M120SF are high performance concretes (hpc), they are assumed to remain saturated due to their low porosity rating and thin microstructure [12].

- H4 specimens are immersed in the Baltic Sea at the Träslövsläge station, Sweden. In this condition, chloride concentration is measured equal to 14 g. $\mathrm{L}^{-1}$.

The concentration at each boundary condition (lab. or in-situ conditions) are specified in Tab. 4.

The initial ionic compositions of the interstitial solution are also summarized in Tab. 4. The concretes M25, BO and M30FA are presaturated in a 4 g.L $\mathrm{L}^{-1}$ solution of $\mathrm{NaOH}$ providing a $p \mathrm{H}$ similar to that of the real interstitial solution. Furthermore, the authors assume that the fluid used for presaturation is similar to the pore solution within the material. Thus, the potential leaching of the concrete samples (e.g. release of potassium and calcium) is neglected. For concretes $\mathrm{C} 1, \mathrm{Mo} 1, \mathrm{Mo} 2$ and $\mathrm{H} 4$, the initial composition of the pore solution is determined thanks to data of extraction of the interstitial solution $[24,29$, ?]. For in-situ concretes (M75SF and M120SF), the composition of the pore solution is considered similar to the one of a high performance cement paste studied by Baroghel-Bouny with a similar mix design (presence of silica fumes [9].

\section{Comparison results}

\subsection{Assessment of $D_{C l^{-}}$and CBIs parameters}

Calibrated values of $\mathrm{D}_{\mathrm{Cl}^{-}}$are compared to experimental measurements of non-steady-state (NSS) [3] and steady-state (SS) [2,43] migration tests (see Fig. 2). Baroghel-Bouny et al. [11] have validated experimentally the equivalence of the effective chloride diffusion coefficients deduced from a NSS migration test and measured by a SS migration test. Indeed, for a large range of cementitious materials, the observed discrepancy of $D_{\mathrm{Cl}^{-}}$values between these two experimental methods is limited.

For the different studied models, $D_{C l^{-}}$values adjusted by inverse analysis are globally of the same order of magnitude. Thus, the calibration of $D_{C l^{-}}$seems slightly impacted neither by the choice of binding description (kind of CBI, taking into account or not competitive binding between ions) or by the choice of transport equations (mono-ionic diffusion or multi-ionic diffusion). In addition, the dispersion observed for the MI1 and MS5 models 


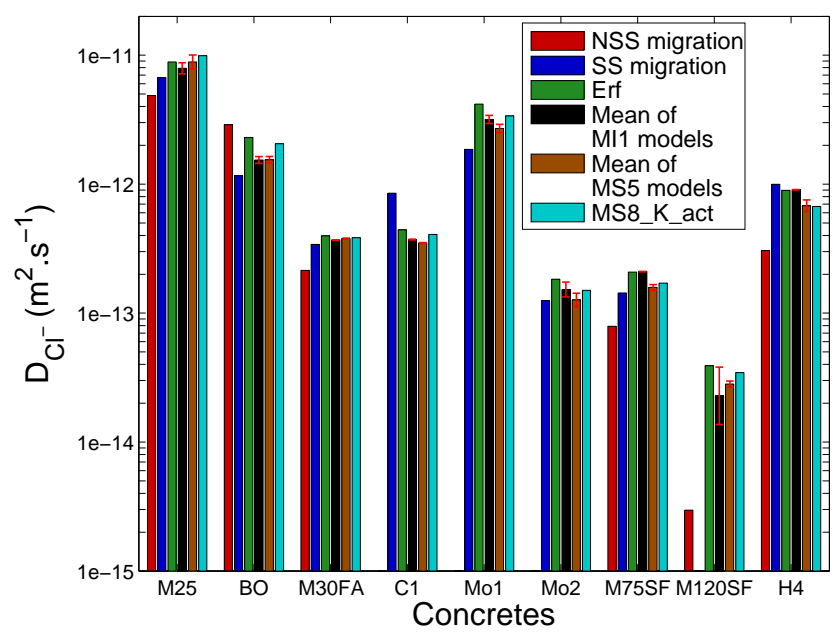

Fig. 2 Effective chloride diffusion coefficients $D_{\mathrm{Cl}^{-}}$obtained from non-steady state (NSS) [3] and steady state (SS) migration tests, and from inverse analysis for the eight studied materials. SS migration test are realized according to the norm [2], except for concretes C1, Mo1, Mo2 and H4 (LMDC test [43]). For models MI1 and MS5, a mean value corresponding to the three kinds of CBI (Freundlich, Langmuir and DL) is considered (the standard deviation is indicated using error bars).

with the three studied CBI descriptions is limited (expect for concrete M120SF) confirming this observation. On the whole, experimental assessments of $\mathrm{DCl}_{\mathrm{Cl}^{-}}$and results of calibration are in good agreement. Nonetheless, it can be noted that the best agreement is found between SS migration test and the numerical inverse analysis methodology presented here. This illustrates the relevancy of a SS migration test to represent an effective diffusion coefficient $D_{\mathrm{Cl}^{-}}$.

Numerical values for concrete M120SF are higher than the value deduced from the NSS migration test (one order of magnitude). This could indicate that the studied chloride ingress models within saturated cementitious materials cannot be extended to a hpc located in a tidal zone. Moreover, this discrepancy between the experimental result and the numerical assessment could also be explained by the lack of experimental data at each exposure time, which imposes to consider two tcc profiles for the calibration of $\mathrm{D}_{\mathrm{Cl}^{-}}$and CBI parameter(s).

A ranking of the studied concretes on the basis of the effective chloride diffusion coefficient can be proposed (by decreasing value of $D_{C l^{-}}$): (i) $\mathrm{M} 25$, (ii) $\mathrm{BO}$ and $\mathrm{H} 4$, (iii) M30FA, M75SF, C1 (iv) M120SF. Concerning the two mortars, Mo1 has an higher effective chloride diffusion coefficient than Mo2. As expected[46], the incorporation of the supplementary cementitious materials, e.g.in this article, silica fume, fly ash and ground granulated blast furnace, induces a significant decrease in the effective chloride diffusion coefficient.

The calibrated values of CBI parameters are provided in Tab. 6. Some results are underlined since the authors suspect an ineffective calibration. As example, in the case of the calibration of the Freundlich isotherm, the parameter $\gamma$ must be under 1 in order to avoid a convex function which is not realistic. The calibration seems to be ineffective only for the concretes M25, M75SF, M120SF. In case of concretes M75SF and M120SF, the unsatisfactory fitting results could be explained by the limited number of available experimental data . Moreover, the previously adopted hypothesis (full saturation of M75SF and M120SF) could be not relevant since in those cases, the selected models do not describe all the significant transport phenomena and the calibration of CBI parameter(s) becomes impossible. For con- 
Table 6 CBIs parameters determined using an inverse analysis method on the tcc profile precised in Tab. 5.The underlined results have to be treated with caution because the authors suspect a non-converging calibration.

\begin{tabular}{|c|c|c|c|c|c|c|c|c|c|}
\hline \multirow{2}{*}{\multicolumn{3}{|c|}{$\begin{array}{l}\text { Models } \\
\text { CBI Parameters }\end{array}$}} & \multirow{2}{*}{$\begin{array}{l}\text { Erf } \\
K\end{array}$} & \multicolumn{2}{|l|}{ MI1_Fre } & \multicolumn{2}{|l|}{ MI1_Lang } & \multicolumn{2}{|l|}{ MI1_DL } \\
\hline & & & & $\mu$ & $\gamma$ & $\alpha$ & $\beta$ & $\alpha^{\prime}$ & $\beta^{\prime}$ \\
\hline \multirow{9}{*}{ 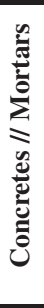 } & \multirow{6}{*}{ 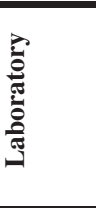 } & M25 & 0.021 & 11.36 & $1.3 .10^{-8}$ & 28.29 & 2.51 & 6.761 & $2.59 .10^{-7}$ \\
\hline & & BO & 0.116 & 17.38 & $\overline{0.189}$ & 0.683 & 0.011 & 216.27 & 3.330 \\
\hline & & M30FA & 0.146 & 0.894 & 0.688 & 0.403 & $5.0 .10^{-3}$ & 76.48 & 0.606 \\
\hline & & C1 & 0.126 & 2.718 & 0.508 & 0.665 & $9.0 .10^{-3}$ & 210.18 & 2.868 \\
\hline & & Mo1 & 0.442 & 20.80 & 0.368 & 1.388 & $5.0 .10^{-3}$ & 438.75 & 1.563 \\
\hline & & Mo2 & 0.335 & 25.16 & 0.300 & 0.674 & $2.0 .10^{-3}$ & 213.08 & 0.680 \\
\hline & \multirow{3}{*}{ 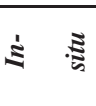 } & M75SF & 0.422 & 0.424 & 1.000 & 0.500 & $4.3 .10^{-4}$ & 134.00 & $4.3 .10^{-8}$ \\
\hline & & M120SF & 0.259 & 9.449 & $\overline{0.542}$ & 2.532 & 0.013 & 82.68 & $8.3 .10^{-7}$ \\
\hline & & H4 & 0.993 & 0.999 & 1.000 & 0.999 & $1.3 .10^{-12}$ & 315.77 & $1.5 .10^{-9}$ \\
\hline \multicolumn{3}{|c|}{ Models } & \multicolumn{2}{|c|}{ MS5_Fre } & \multicolumn{2}{|c|}{ MS5_Lang } & \multicolumn{2}{|l|}{$\overline{\text { MS5_DL }}$} & MS8_K_act \\
\hline \multicolumn{3}{|c|}{ CBI Parameters } & $\mu$ & $\gamma$ & $\alpha$ & $\beta$ & $\alpha^{\prime}$ & $\beta^{\prime}$ & $C_{a d s}$ \\
\hline \multirow{9}{*}{ 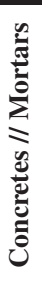 } & \multirow{6}{*}{ 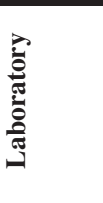 } & M25 & 11.86 & $6.8 .10^{-8}$ & 99.22 & 3.55 & 2.2098 & $8.5 .10^{-8}$ & 19.54 \\
\hline & & BO & 16.06 & $\overline{0.203}$ & 0.678 & 0.010 & 130.98 & 2.194 & 106.82 \\
\hline & & M30FA & 0.826 & 0.717 & 0.236 & $1.8 .10^{-3}$ & 41.78 & 0.471 & 116.43 \\
\hline & & C1 & 2.677 & 0.510 & 0.605 & $8.1 .10^{-3}$ & 106.31 & 1.745 & 257.89 \\
\hline & & Mo1 & 16.36 & 0.404 & 1.129 & $3.7 .10^{-3}$ & 340.21 & 1.660 & 613.13 \\
\hline & & Mo2 & 11.25 & 0.430 & 0.549 & $1.5 .10^{-3}$ & 186.71 & 1.104 & 1063.68 \\
\hline & \multirow{3}{*}{ 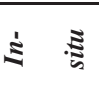 } & M75SF & 0.403 & 1.000 & 0.409 & $3.3 .10^{-5}$ & 46.82 & 0.273 & 786.58 \\
\hline & & M120SF & 0.237 & $\overline{1.000}$ & 0.248 & $1.5 .10^{-5}$ & 4.884 & 0.044 & 440.87 \\
\hline & & H4 & 0.9415 & $\overline{1.000}$ & 0.9415 & $6.7 .10^{-11}$ & 56.85 & 0.1916 & 1447.02 \\
\hline
\end{tabular}

crete M25, the non-converging calibration is unexpected. These results will be investigated more in details in the section 4.5.

When considering concrete $\mathrm{H} 4$, the result of the calibration points out that the relevant $\mathrm{CBI}$ is a linear function. As a matter of fact, when applying Freundlich or Langmuir isotherms, the calibration results converge to a linear shape since the $\gamma$ (Freundlich) and $\beta$ (Langmuir) parameters tend towards 1 and 0, respectively. Saillio [34] observed also linear CBIs for various concretes (OPC, concretes incorporating metakaolins, fly ash and groundgranulated blast-furnace slag) cured with water during more than one year. According to his research work, in the range of fcc between 0 and 14 g.L. ${ }^{-1}$, the sites of the solid matrix on which chloride ions can be adsorbed, are not all saturated. Consequently, the non-linear feature of the CBI cannot be detected in this case.

As previously mentioned in the literature [13], the parameters $\gamma, \beta$ and $\beta^{\prime}$ of the Freundlich, Langmuir and DL CBIs, respectively, should be intrinsic. This is clear at least for parameters $\beta$ and $\beta^{\prime}$, since they correspond to a ratio of equilibrium constants characterizing the binding mechanism. However, whatever the considered parameter $\left(\gamma, \beta\right.$ or $\left.\beta^{\prime}\right)$, a large dispersion is observed here. This illustrates that the inverse problem is likely to be under-determined and that there is more than one solution for the triplet $\left(D_{\mathrm{Cl}^{-}}+\right.$two $\mathrm{CBI}$ parameters). This problem can be overcome by linking the two CBI parameters using Eq.3 at the sample surface [13].

Let us consider the other parameters, $\mu, \alpha$ and $\alpha^{\prime}$ of the Freundlich, Langmuir and DL CBIs, respectively. Due to the high dispersion of $\gamma, \beta$ and $\beta^{\prime}$, no clear ranking of concretes according to their binding capacity can be determined. However, parameters $K$ and $C_{a d s}$, used in CBI models with only one unknown variable, seem to present a physico-chemical meaning by being correlated to the amount of binder within the concrete and its capacity to bind physically ions. Thus, a ranking of the studied concretes (excepted H4) on the basis 
of the capacity to bind chloride ions can be proposed (by increasing order): (i) M25, (ii) BO, C1 and M30FA, (iii) M120SF and (iv) M75SF. Concrete H4 is excluded of this ranking since the assessed capacity of chloride binding is not consistent with the composition of this concrete. Concerning the two mortars, Mol has an higher capacity to bind chloride ions than Mo2.

Fixing the material, the comparison of models using the same kind of CBI (MI1_Fre / MS5_Fre or MI1_Lang / MS5_Lang or MI1_DL / MS5_DL), but different approaches of transport indicates similar values for each parameter of the CBIs (except the ineffective calibration). Thus, the description of ion transport (mono-ionic diffusion or multi-ionic diffusion) seems to weakly influence the calibration of the CBI parameters.

\subsection{Evaluation of the calibration process}

The accuracy of the calibration is evaluated using the indicator $R_{a d j}^{2}$ (see Fig. 3). All models provide satisfactory fitting results except in the cases of concretes M120SF and H4 (only for the models MS5_DL). Excluding M120SF and H4, $R_{a d j}^{2}$ values are higher than 0.98 and the dispersion of $R_{a d j}^{2}$ remains limited $\left(\sigma\left(R_{a d j}^{2}\right)<6.10^{-3}\right)$. For concrete $\mathrm{H} 4, R_{a d j}^{2}$ values are different depending on the considered model: (i) for the monoionic models (Erf and MI1), they are close to 0.9875, (ii) for the models MS5_Fre, MS5_Lang and MS8_K_act, they are close to 0.98, (iii) for the model MS5_DL, it is equal to 0.967. In this last case, a visual check (using Fig. 4) is needed to ensure the success of the calibration. Models MI1_Lang, MI1_DL provide slightly better fitting results than other models.

Illustrations of fitting results in term of tcc profiles are represented in Fig. 4 for four materials (BO, M75SF, M120SF and H4 representing one laboratory concrete and three insitu concretes). The calibration process is qualitatively conclusive for all concretes (even the concrete M120SF) since the discrepancy between experimental data and numerical profiles remains limited. The combined use of the statistical indicator $R_{a d j}^{2}$ and the visual check ensures the success of calibration.

\subsection{Prediction of total chloride content profiles}

Once the chloride ingress models are calibrated, it is possible to predict at any age tcc and fcc profiles. The statistical indicator $R_{a d j}^{2}$ is again used in order to assess the accuracy of the predicted numerical tcc profiles according to the available experimental data at the different ages specified in Tab. 5. As expected, $R_{a d j}^{2}$ values (see Fig. 5) are lower than those corresponding to the calibration procedure.

Substantially different results are obtained between concretes immersed in a saline solution (artificial solution or seawater) and concretes located in a tidal zone. Indeed, a large dispersion in the results is observed for concretes M75SF and M120SF $\left(0.25<R_{a d j}^{2}<0.95\right)$. This feature implies that the tcc profiles prediction is not conclusive in that case. There are three possible explanations:

- In case of concrete M120SF, the thickness affected by the wetting and drying cycles (the so-called convection zone) is not negligible. Even if the convection zone is thin, chloride ingress is significantly modified in comparison to the saturated case. From a practical point of view this problem is overcome by modifying the boundary conditions and increasing the chloride content at the specimen surface [10]. Consequently, chloride ingress models which neglect moisture transport, are not relevant in this case. 


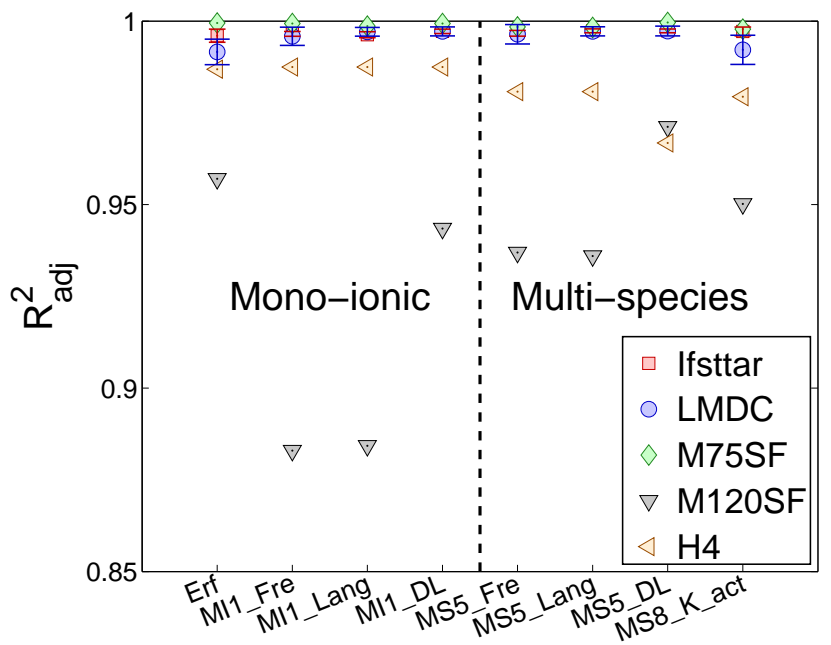

(a)

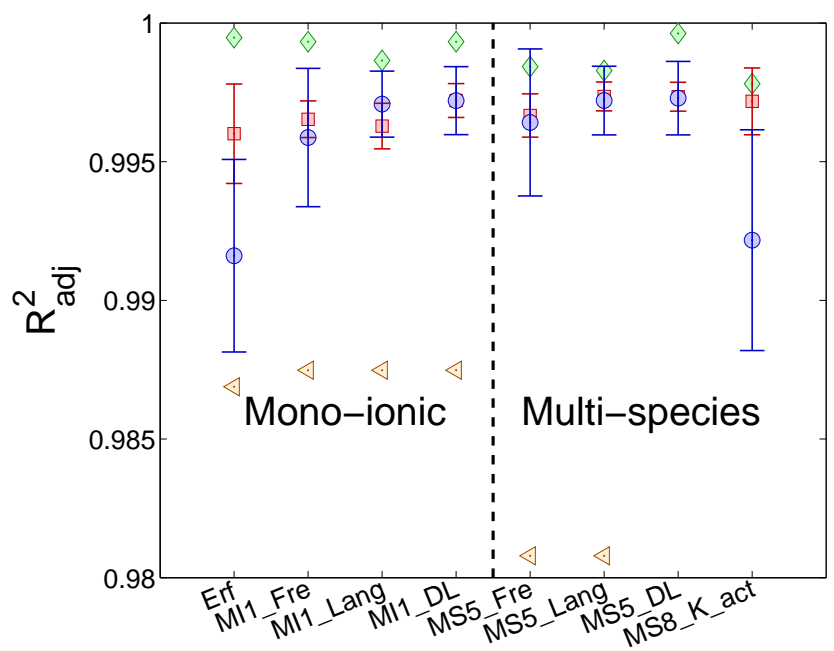

(b)

Fig. 3 Comparison on the basis of $R_{a d j}^{2}$ of the calibration results for each studied model. Each square ( $\square$ ) and each circle (०) represent the mean value for the laboratory results. Single symbols are plotted for concretes $\operatorname{M75SF}(\diamond), \operatorname{M120SF}(\nabla)$ and H4 $(\triangleleft)$. Each error bar represents the standard deviation. Concretes M75SF and M120SF are drawn separately because of the high dispersion of the results. The second figure* illustrates a focus for the best results, i.e. $R_{a d j}^{2}$ values between 0.98 and 1 .

- An improved description of the involved dissolution-precipitation reactions is necessary.

- Carbonation has occurred in the first millimeters leading to a lower binding capacity [35] (not considered in the models).

Note that for concrete H4, the predictions of the model MS8_K_act are not satisfactory $\left(R_{a d j}^{2} \simeq 0.82\right)$. Moreover, in case of model MS5_DL, mean $R_{a d j}^{2}$ value is close to 0.96. A visual check using Fig. 4(d) is necessary to ensure the success of calibration. By their defi- 


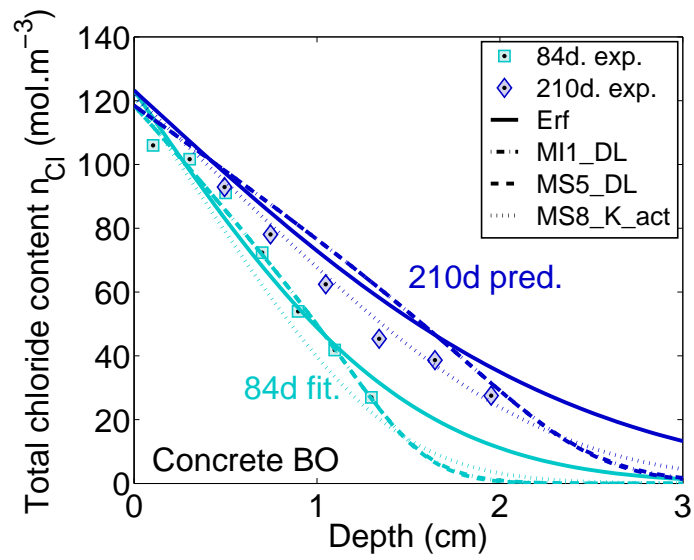

(a)

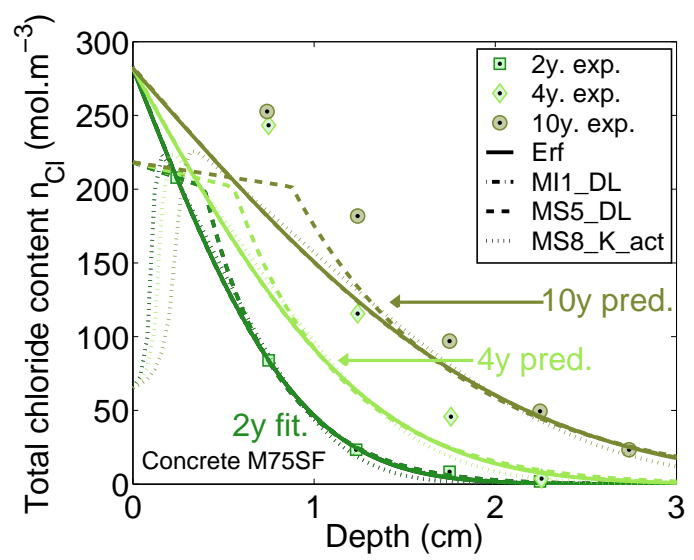

(b)

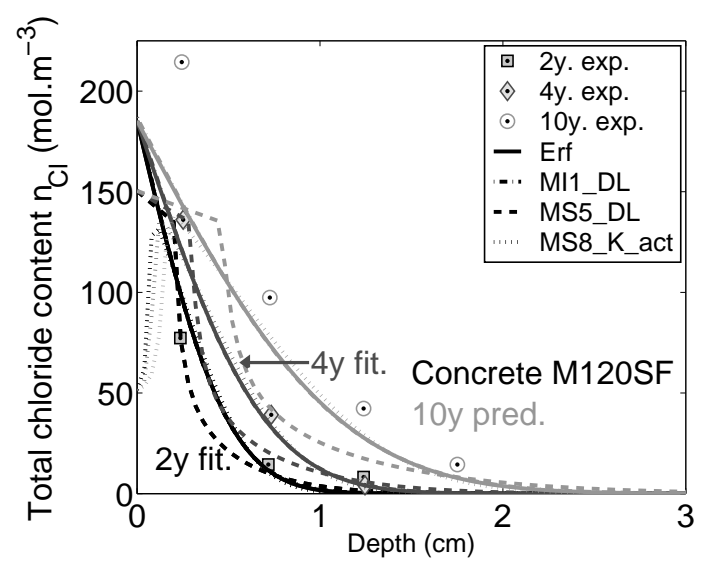

(c)

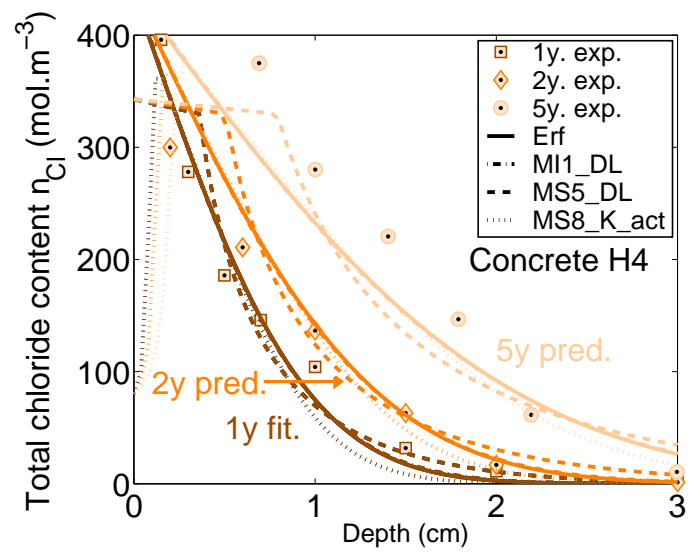

(d)

Fig. 4 Fitted and predicted tcc profiles for concretes BO (a), M75SF (b), M120SF (c) and H4 (d). For each concrete, the experimental tcc profile corresponding to the first time of exposure is used to fit the CBI parameter(s) and $D_{C l^{-}}$. Then, tcc profiles at various following exposure times are predicted. To make the display clearer, only the models Erf, MI1_DL, MS5_DL and MS8_K_act are plotted. 


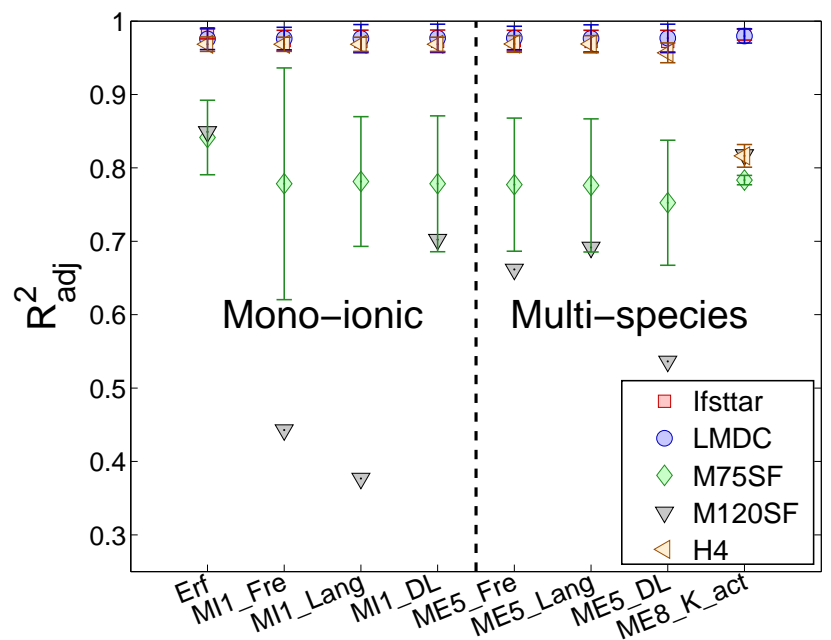

(a)

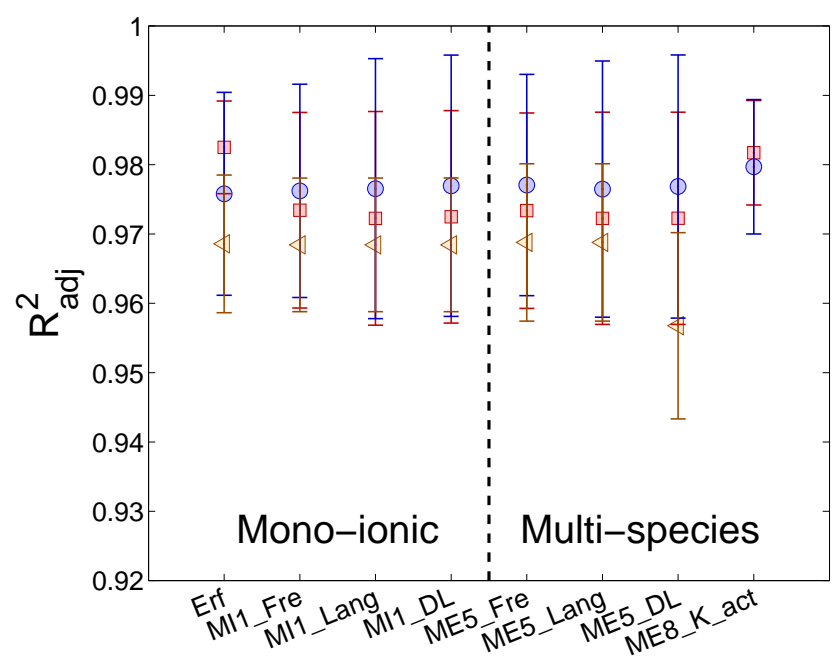

(b)

Fig. 5 Comparison results of prediction of tcc profiles at other exposure times than the times used for the fitting for each studied model. Each square $(\square)$ and each circle (०) represent the mean value for the laboratory results (origin from two different references). The left triangle $(\triangleleft)$ corresponds to the concrete H4. Single values are plotted for concretes M75SF $(\diamond)$ and M120SF $(\nabla)$. The error bar represents the standard deviation. The second figure* focuses on the best results $\left(R_{a d j}^{2}\right.$ values between 0.92 and 1$)$.

nition, these two models are not relevant to describe a linear feature. Indeed, considering a linear CBI in case of concrete $\mathrm{H} 4$, the model calibration is successful and then, the prediction of chloride ingress is compatible with experimental data. Model MS8_K_act describes a competitive adsorption of ions onto the solid matrix. Model MS5_DL takes into account the $p \mathrm{H}$ impact on chloride ion binding: the higher is the $p \mathrm{H}$ value, more the hydroxide ions compete the chloride ions for the adsorption on the solid matrix. Thus, the difference in $p \mathrm{H}$ between seawater and interstitial solution implies a non linear CBI. As the concrete H4 spec- 
imens are immersed in seawater (i.e. $\mathrm{H}<13$ and various ions are present), the numerical CBIs calculated by these two models have a non linear shape.

Dealing with concretes immersed in a saline solution and excluding the models MS5_DL and MS8_K_act, $R_{a d j}^{2}$ results are quite similar: mean $R_{a d j}^{2} \simeq 0.975$ and standard deviation around 0.015 . For the concretes tested in laboratory condition, the model MS8_K_act provides slightly better prediction: mean $R_{a d j}^{2} \simeq 0.98$ and $\sigma\left(R_{a d j}^{2}\right) \simeq 0.010$ ).

These results are confirmed by checking in Fig. 4 the predicted shape of tcc profiles for concretes BO (210 days), M75SF (4 and 10 years), M120SF (10 years) and H4 (2 and 5 years). The prediction is conclusive for concrete BO, as opposed to M75SF, M120SF and H4. Indeed, in Figs. 4(b), 4(c), for the concretes M75SF and M120SF, the studied models underestimate the total chloride content in the vicinity of the specimen surface. This could illustrate the fact that the selected models do not take into account the consequences of wetting and drying cycles on the distribution of chloride ions [19,30]. In Fig. 4(d), in case of the concrete $\mathrm{H} 4$, the prediction of the tcc at 2 and 5 years seems qualitatively in agreement with the experimental data, excluding the models MS5_DL and MS8_K_act. As previously detailed in this section, these two last models cannot describe the linear shape of the CBI and thus, the difference between experimental data and numerical predictions for the first millimeters of material from the specimen surface is important.

\subsection{Prediction of free chloride concentration profiles}

The prediction of fcc profiles is as necessary as that of tcc profiles since no clear trend indicates if the chloride threshold amount initiating the corrosion must be expressed using total chloride content or free chloride concentration. Only fcc profiles of laboratory materials (M25, BO and M30FA) are compared here to simulations (see Tab. 5).

The indicator $R_{a d j}^{2}$ related to the prediction of fcc profiles is shown in Fig. 6(a). Results for concrete M25 are not satisfactory since $R_{a d j}^{2}<0.95$ and the dispersion is high. This could be explained by the characteristics of concrete M25 which has a so low durability $(w / c=0.84)$ that it is difficult to reach enough stability during the placing of the fresh material. Thus, the homogeneity in term of microstructure properties is low, e.g. between the specimen used for the calibration at a given time and the one for the determination of a fcc profile at another time. On the contrary, the prediction for concrete M30FA is satisfactory for all types of model $\left(R_{a d j}^{2}>0.985\right)$. For concrete $\mathrm{BO}$, the predictions obtained with models MI1_Lang, MI1_DL, MS5_Lang, MS5_DL and MS8_K_act are satisfactory $\left(R_{a d j}^{2} \simeq 0.974\right)$ whereas those obtained with other models are lower $\left(R_{a d j}^{2}<0.94\right)$ but remain of good quality.

Comparisons between experimental data and predictions performed for concretes M25, BO and M30FA by the above models are provided in Fig. 6(b). The previous observations about the prediction performances in term of $R_{a d j}^{2}$ are confirmed. No model predicts with enough accuracy fcc profiles for concrete M25. Note that model Erf provides a faster kinetics of chloride ingress than other models and experimental profiles (see concrete BO in particular). Qualitatively, it is confirmed that predictions performed with a non linear CBI description are closer to the reality. 


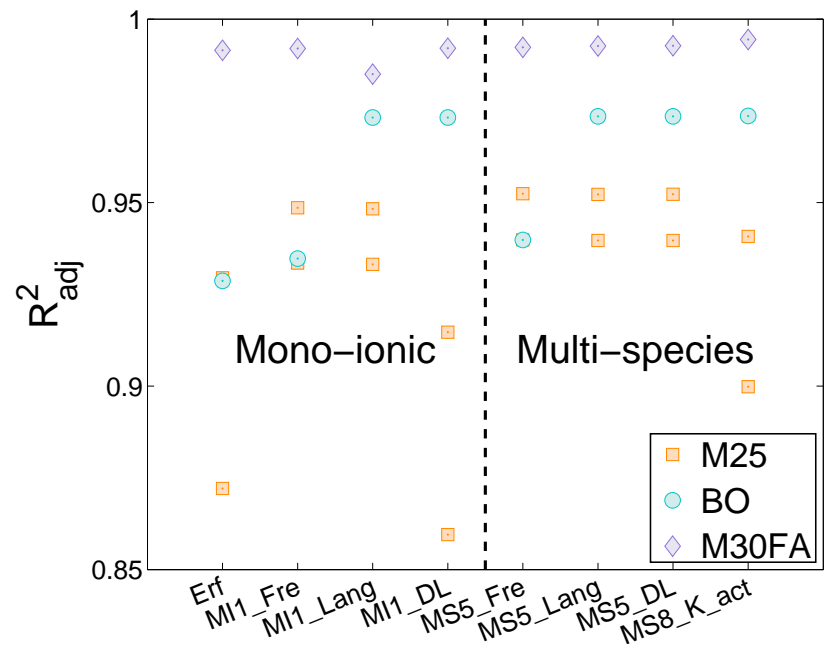

(a)

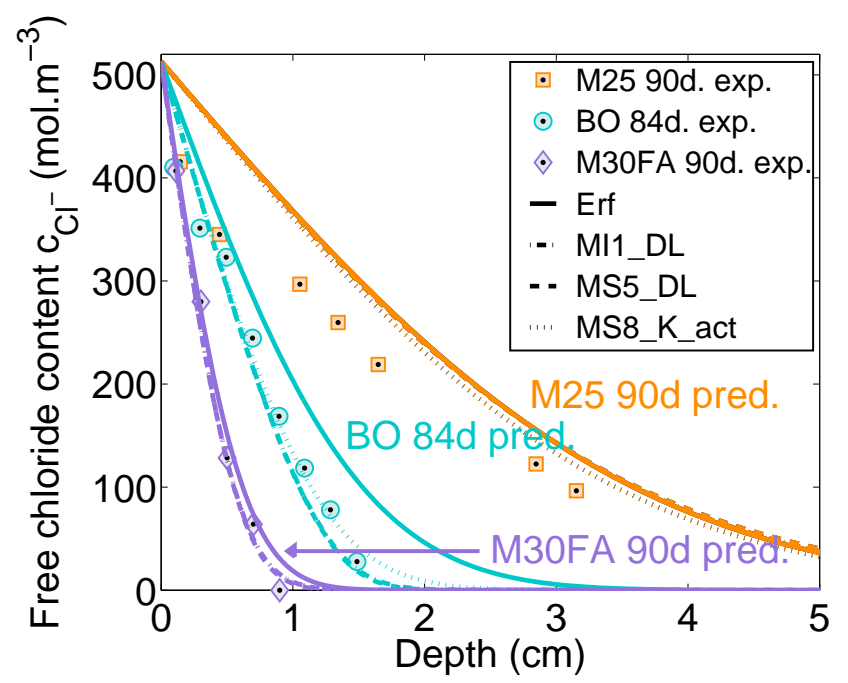

(b)

Fig. 6 (a) Comparison results of predicting fcc profiles using $R_{a d j}^{2}$. Squares ( $\square$ ), circles (०) and diamonds $(\diamond)$ represent the concretes M25, BO and M30FA, respectively. (b): Predicted fcc profiles for concretes M25, BO and M30FA using fitted values for $\mathrm{D}_{\mathrm{Cl}^{-}}$and parameters of CBIs presented in Tab. 6 .

\subsection{Shapes of the numerical chloride binding isotherms}

Different examples of numerical CBIs (concretes M25, BO and M75SF) are illustrated in Fig. 7. These isotherms are plotted combining predicted tcc and fcc values at any depth and at a given age.

Available experimental data are also reported in Fig. 7 for concretes M25 (90 and 150 days) and BO (90 days). They are obtained by the so-called profile method which requires both tcc and fcc data at the same age [13]. The discrepancy observed between numerical 


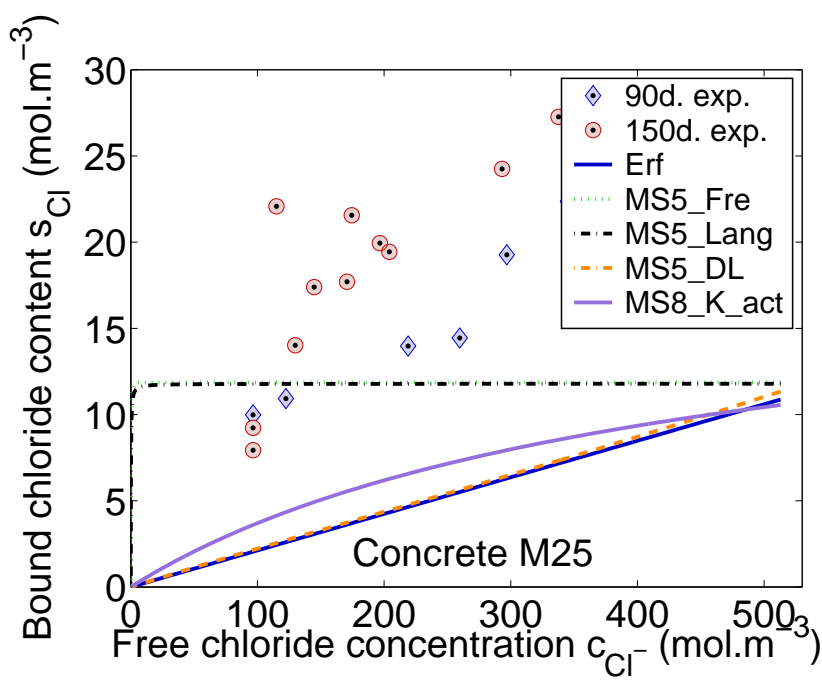

(a)

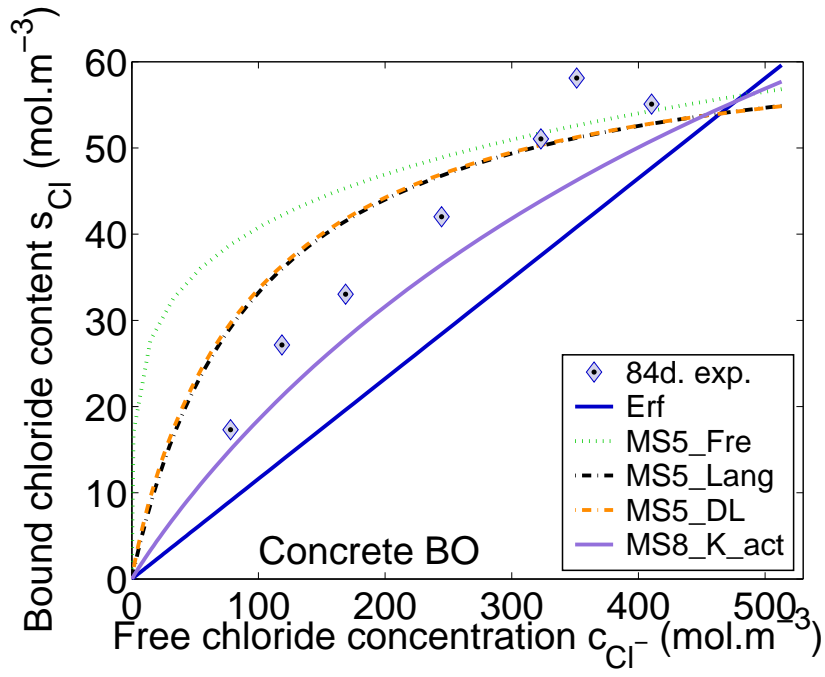

(b)

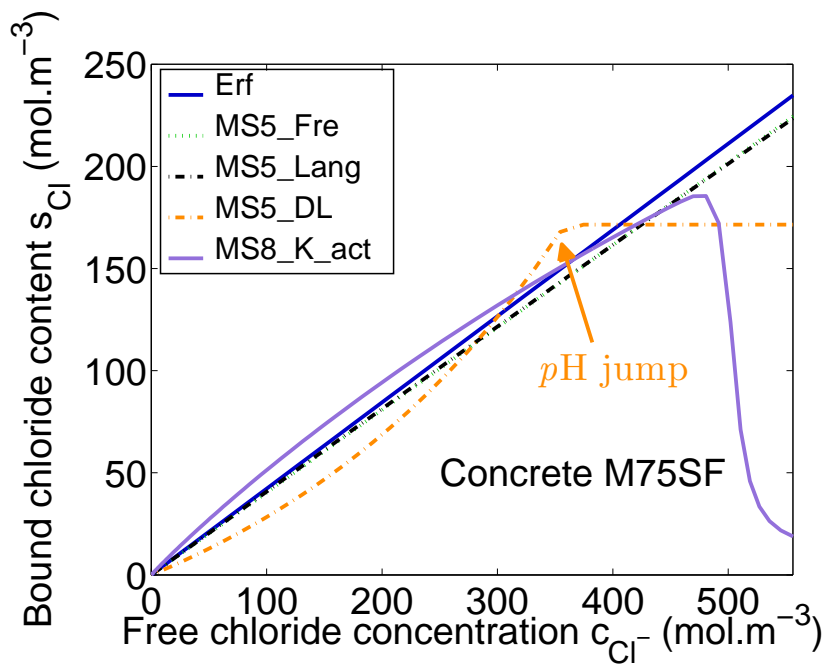

(c)

Fig. 7 Calculated chloride binding isotherms for all studied models: (a) concrete M25 (b) concrete BO (c) concrete M75SF. For concretes M25 and BO, simulated CBIs using the MI1_Fre, MI1_Lang and MI1_DL models are similar to that assessed using the MS5_Fre, MS5_Lang and MS5_DL models, respectively. For concrete M75SF, CBIs which are not illustrated are between MS5_Lang and MS5_Fre CBIs. 
CBIs and experimental data has two origins: the error on the free chloride concentration (x-axis) and the error on the total chloride concentration (y-axis).

Dealing with concrete M25 (see Fig. 7(a)), none of the proposed descriptions is actually conclusive since a large discrepancy exists between experimental data and numerical CBIs. An explanation has been already pointed out in section 4.4 regarding the high level of heterogeneity of this peculiar concrete which is reflected in experimental profiles, and thus in experimental CBI (see Fig. 7(a)). The studied models are more or less too sensitive to the dispersion of these profiles: two-parameter CBI models (with a higher degree of freedom than the one-parameter CBI models) are closer to the experimental data. Three shapes of numerical CBI are observed. Whatever is the transport description (mono-ionic diffusion or multi-ionic diffusion), the Freundlich and Langmuir isotherms tend towards a constant function whereas the DL description is almost linear. Only the competitive adsorption description seems to present a relatively realistic shape.

Considering Fig. 7(b), numerical CBIs for the concrete BO present common shape. Again, no influence of the description of ion transport is observed. Comparison between numerical results and experimental data reveals that all descriptions are acceptable: the Freundlich, Langmuir and DL isotherms seem to overestimate the binding (except at a very high fcc), unlike of the linear and competitive adsorption descriptions.

For concrete M75SF (see Fig. 7(c)), no experimental data are available. Nevertheless, interesting elements can be pointed out about the shapes of numerical CBIs. Considering the Freundlich and Langmuir isotherms, the shape of the CBIs looked like to a linear function. This confirms the observations made in section 4.1 of the non-converging calibration in these cases.

Dealing with models MS5_DL and MS8_K_act, when the bound chloride content (bcc) is ploted as a function of fcc, it involves a projection since the bcc also depends on the free concentration of hydroxide ions (MS5_DL) as well as of all other ions (MS8_K_act). The calculated $\mathrm{CBI}$ is a simple path on the hyperplane. Consequently, Fig. 7 only represents a projection of $s_{C l}$ as a function of $c_{C l^{-}}$for model MS8_K_act.

In case of the DL isotherm, a maximal amount of bound chloride is reached at high fcc. A numerical error explains this peculiar shape. It is related to the concentration $c_{\mathrm{OH}^{-}}$which is fixed using the electro-neutrality (see section 3.1). Indeed, respecting the concentration of chloride and alkaline ions, $p \mathrm{H}$ is calculated equal to 1.2 for the seawater boundary condition (see Fig. 8). The $p \mathrm{H}$ jump $(13 \rightarrow 1.2)$ coincides with the apparition of the plateau in Fig. 7(c). At acidic $p \mathrm{H}$, mainly chloride ions are adsorbed (bound hydrogen content can be neglected) and the maximal bcc is thus reached. On the contrary, at a $p \mathrm{H}$ close to the initial value $(p \mathrm{H}$ $\simeq 13$ ), a competitive adsorption $\left(\mathrm{Cl}^{-} / \mathrm{OH}^{-}\right)$onto the solid matrix occurs.

The CBI assessed using model MS8_K_act is also unusual. A classical shape of CBI is observed except at high fcc since the amount of bound chloride ions falls drastically illustrating a severe competitive adsorption between ions (sulfate ions tend to be bound instead of chloride ions). On the contrary of the DL description, hydroxide ions do not influence the shape of CBI. Indeed, adding the buffer role of $\mathrm{CH}$ in the model MS8_K_act, the above-mentioned artifact regarding the calculation of $p \mathrm{H}$ and its consequences on the shape of CBI remain limited. For the seawater boundary condition, $p \mathrm{H}$ value is calculated equal to 12. Thus, whatever the depth and the exposure time, $p \mathrm{H}$ value are included between 12 and the initial value (13-13.5). This observation can open up new interesting horizons for research. Indeed, it is commonly assumed that in case of cementitious materials placed in-situ in a tidal zone, the particular shape of tcc profiles as a bell curve is related to the wetting-drying phenomena. The assumed competitive adsorption on solid matrix could also explain this peculiar shape of tcc profiles. 


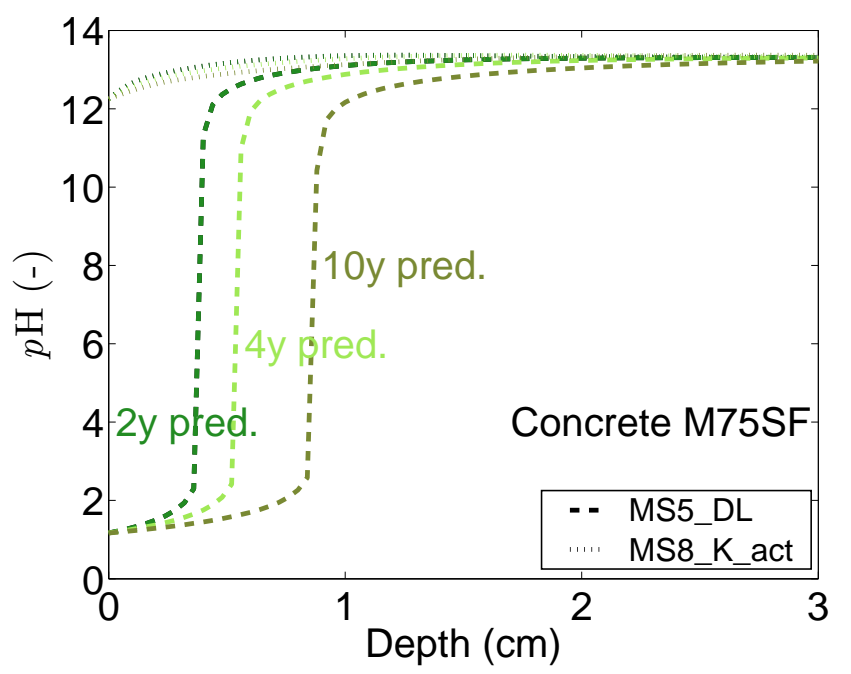

Fig. 8 Calculated $p \mathrm{H}$ profiles for concrete M75SF.

\section{Conclusion}

A comprehensive benchmark of chloride ingress models into saturated cementitious materials have been performed. For this purpose, a database of nine concretes and mortars, including laboratory and in-situ data have been used. The adopted calibration process is based on inverse analysis of total chloride content profiles using different models. The success of the calibration has been validated using the indicator $R_{a d j}^{2}$ and a visual check of numerical tcc profiles. Finally, predictions of tcc and fcc profiles have been provided. The same process of validation has been performed to evaluate the discrepancy between numerical predictions and experimental data.

The following conclusions have been drawn from the above benchmark:

- The selected models provide satisfactory predictions only in the case of concretes fully immersed in a saline solution. In case of materials in tidal zone, improvements of the models is needed to account for the effects of wetting-drying cycles on chloride ingress and/or dissolution-precipitation phenomena of hydration products, and carbonation.

- The benchmark indicates that all levels of modeling provide reliable predictions in case of fully immersed concrete specimens. If a higher precision is researched, distinctions can be proposed according to the objective: for tcc predictions, model MS8_K_act is recommended (only for a full immersion in an alkaline solution) whereas for fcc predictions, the models MS5_Fre or MS5_Lang are more relevant.

- Considering the description adapted from Kari et al.[23] of a competitive adsorption onto the solid matrix, induced an unexpected conclusion: in case of cementitious materials in tidal zone, the particular shape of the tcc profiles, commonly explained by the effect of wetting-drying cycles, could result from the competitive ion binding as well. Calculations seem to indicate that sulfate ions compete with chloride ions in the adsorption onto the solid matrix.

This study has investigated different levels of refinement for chloride ingress models within saturated concretes. Thanks to these conclusions, the selected models can be imple- 
Table 7 The equilibrium constants K for physical adsorption onto $C-S-H$ [23].

\begin{tabular}{|l|l|}
\hline Reaction equations & K \\
\hline$\equiv \mathrm{SiOH}+\mathrm{OH}^{-} \Leftrightarrow \equiv \mathrm{SiO}^{-}+\mathrm{H}_{2} \mathrm{O}$ & $K_{\mathrm{OH}}=10^{-12.70}$ \\
$\equiv \mathrm{SiOH}+\mathrm{Ca}^{2+} \Leftrightarrow \equiv \mathrm{SiOCa}^{+}+\mathrm{H}^{+}$ & $K_{\mathrm{Ca}}=10^{-9.40}$ \\
$\equiv \mathrm{SiOH}+\mathrm{Ca}^{2+}+\mathrm{Cl}^{-} \Leftrightarrow \equiv \mathrm{SiOCaCl}+H^{+}$ & $K_{\mathrm{Ca}}=10^{-6.00}$ \\
$\equiv \mathrm{SiOH}+\mathrm{Ca}^{2+}+\mathrm{SO}_{4}^{2-} \Leftrightarrow \equiv \mathrm{SiOCaSO}{ }_{4}^{-}+\mathrm{H}^{+}$ & $K_{\mathrm{CaSO}_{4}}=10^{-8.90}$ \\
$\equiv \mathrm{SiOH}+\mathrm{Na}^{+} \Leftrightarrow \equiv \mathrm{SiONa}+\mathrm{H}^{+}$ & $K_{\mathrm{Na}}=10^{-13.64}$ \\
$\equiv \mathrm{SiOH}+\mathrm{K}^{+} \Leftrightarrow \equiv \mathrm{SiOK}+\mathrm{H}^{+}$ & $K_{\mathrm{K}}=10^{-13.64}$ \\
$\equiv \mathrm{SiOH}+\mathrm{Cl}^{-} \Leftrightarrow \equiv \mathrm{SiOHCl}$ & $K_{\mathrm{Cl}}=10^{-0.35}$ \\
\hline
\end{tabular}

mented in a reliability framework. This work could help for a more comprehensive sensitivity analysis related to input data.

\section{A Description of ion adsorption onto $C-S-H$ [23]}

Tab. 7 resumes the considered equations describing the competitive adsorption onto solid matrix. The authors add the hypothesis that the capacity of solid matrix to adsorb is constant for all ions. Constants of adsorption reaction are assumed to be equal to those of adsorption reactions onto $C-S-H$. Such hypothesis is equally used by some authors of the literature [20,23]. Thus, analytical relationships (see Eqs. 13) between the content of bound ions and the free concentration of ions can be written. First, let us note the denominator $D$ and the vector $\mathbf{C}$ as:

$$
\begin{aligned}
& D=1+K_{\mathrm{OH}} c_{\mathrm{OH}^{-}}+\left(K_{\mathrm{Ca}}+K_{\mathrm{CaSO}_{4}} c_{\mathrm{SO}_{4}^{2-}}+K_{\mathrm{CaCl} c_{\mathrm{Cl}^{-}}}\right) \frac{c_{\mathrm{Ca}^{2+}}}{c_{\mathrm{H}^{+}}} \\
& +\frac{K_{N a} c_{N a^{+}}+K_{K} c_{K^{+}}}{c_{H^{+}}}+K_{C l} c_{C l^{-}} \\
& \mathbf{C}=\left(c_{\mathrm{Cl}^{-}} c_{\mathrm{OH}^{-}} c_{\mathrm{SO}_{4}^{2-}} c_{\mathrm{Na}^{+}} c_{\mathrm{K}^{+}} c_{\mathrm{Ca}^{2+}}\right)
\end{aligned}
$$

Analytical relationships are then:

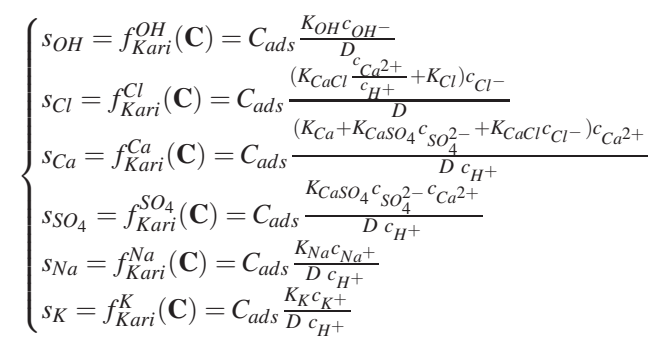

where the parameter $C_{a d s}$ has to be calibrated.

\section{References}

1. NF EN 1992-1-1 Eurocode 2 - design of concrete structures - Part 1-1: general rules and rules for buildings (2005)

2. XP P18-461: Testing hardened concrete - chloride ions migration accelerated test in steady-state conditions - determining the effective chloride ions diffusion coefficient (French standard). French association of normalization (AFNOR) (2012)

3. XP P18-462: Testing hardened concrete - chloride ions migration accelerated test in non-steady-state conditions - determining the apparent chloride ions diffusion coefficient (French standard). French association of normalization (AFNOR) (2012) 
4. NF EN 206-1 Concrete - specification, performance, production and conformity (2014)

5. Alexander, M., Ballim, Y., Stanish, K.: A framework for use of durability indexes in performance-based design and specifications for reinforced concrete structures. Materials and Structures 41(5), 921-936 (2008). DOI 10.1617/s11527-007-9295-0. URL http://dx.doi.org/10.1617/s11527-007-9295-0

6. Aramata, A., Bockris, J., White, R., Conway, B.: Modern Aspects of Electrochemistry. Plenum Press, New York (1997)

7. Arya, C., Buenfeld, N., Newman, J.: Factors influencing chloride-binding in concrete. Cement and Concrete Research 20(2), 291 - 300 (1990). DOI http://dx.doi.org/10.1016/0008-8846(90)90083-A. URL http://www.sciencedirect.com/science/article/pii/000888469090083A

8. Balonis, M., Lothenbach, B., Saout, G.L., Glasser, F.P.: Impact of chloride on the mineralogy of hydrated portland cement systems. Cement and Concrete Research 40(7), 1009 - 1022 (2010). DOI http://dx.doi.org/10.1016/j.cemconres.2010.03.002. URL http://www.sciencedirect.com/science/article/pii/S000888461000058X

9. Baroghel-Bouny, V.: Characterization of cement pastes and concretes-methods, analysis, interpretations (in French). Ph.D. thesis, ENPC (LCPC Publ., Paris) (1994)

10. Baroghel-Bouny, V.: Concrete design for a given structure service life-durability management with regards to reinforcement corrosion and alkali-silica reaction. state-of-the-art and guide for the implementation of a predictive performance approach based upon durability indicators. Scientific and Technical Documents of AFGC (AFGC, Paris, issue in French: 2004 \& issue in English: 2007) (2007)

11. Baroghel-Bouny, V., Kinomura, K., Thiéry, M., Moscardelli, S.: Easy assessment of durability indicators for service life prediction or quality control of concretes with high volumes of supplementary cementitious materials. Cement and Concrete Composites 33(8), 832 - 847 (2011). DOI http://dx.doi.org/10.1016/j.cemconcomp.2011.04.007. URL http://www.sciencedirect.com/science/article/pii/S0958946511000801

12. Baroghel-Bouny, V., Thiéry, M., Wang, X.: Performance-based assessment of durability and prediction of rc structure service life: transport properties as input data for physical models. Materials and Structures pp. 1-23 (2013). DOI 10.1617/s11527-013-0144-z. URL http://dx.doi.org/10.1617/s11527-013-0144-Z

13. Baroghel-Bouny, V., Wang, X., Thiéry, M., Saillio, M., Barberon, F.: Prediction of chloride binding isotherms of cementitious materials by analytical model or numerical inverse analysis. Cement and Concrete Research 42(9), 1207 - 1224 (2012). DOI http://dx.doi.org/10.1016/j.cemconres.2012.05.008. URL http://www.sciencedirect.com/science/article/pii/S0008884612001251

14. Bickley, J., Hooton, R.D., Hover, K.C.: Preparation of a performance-based specification for cast-inplace concrete. Tech. rep., RMC Research Foundation (2006)

15. Chaussadent, T., Arliguie, G.: Afrem test procedures concerning chlorides in concrete: Extraction and titration methods. Materials and Structures 32(3), 230-234 (1999). DOI 10.1007/BF02481520. URL http://dx.doi.org/10.1007/BF02481520

16. Codina, M., dit Coumes, C.C., Bescop, P.L., Verdier, J., Ollivier, J.: Design and characterization of low-heat and low-alkalinity cements. Cement and Concrete Research 38(4), 437 - 448 (2008). DOI http://dx.doi.org/10.1016/j.cemconres.2007.12.002. URL http://www.sciencedirect.com/science/article/pii/S0008884607003092

17. De Larrard, F., Baroghel-Bouny, V.: Ageing of concrete in natural environments: an experiment for the 21 st century. I : general considerations and initial mechanical properties of tested concrete (in French), vol. 225. Bulletin des laboratoires des Ponts et Chaussées (2000)

18. Engelund, S., Edvardsen, C., Mohr, L.: General guidelines for durability design and redesign. Report R15, EU-Brite EuRam III project BE95-1347 DuraCrete. Probabilistic performance based durability design of concrete structures (2000)

19. Francy, O.: Modelling of chloride ions ingress in partially water saturated mortars (in french). Ph.D. thesis, Paul Sabatier Univ., Toulouse (1998)

20. Henocq, P.: Modeling of the ion interactions to the surface of the calcium silicate hydrate (in French). Ph.D. thesis, Cergy-Pontoise univ. (2005)

21. Johannesson, B., Yamada, K., Nilsson, L.O., Hosokawa, Y.: Multi-species ionic diffusion in concrete with account to interaction between ions in the pore solution and the cement hydrates. Materials and Structures 40(7), 651-665 (2007). DOI 10.1617/s11527-006-9176-y. URL http://dx.doi.org/10.1617/s11527-006-9176-y

22. Justnes, H.: A review of chloride binding in cementitious systems. Nordic concrete research publications 21, 48-63 (1998)

23. Kari, O., Elakneswaran, Y., Nawa, T., Puttonen, J.: A model for a long-term diffusion of multispecies in concrete based on ioncement-hydrate interaction. Journal of Materials Science 48(12), 4243-4259 (2013). DOI 10.1007/s10853-013-7239-3. URL http://dx.doi.org/10.1007/s10853-013-7239-3

24. Khitab, A.: Modelling of ionic transfers in saturated porous media: application to the penetration of chlorides into cementitious materials (in French). Ph.D. thesis, INSA Toulouse (2005) 
25. Marchand, J., Samson, E., Maltais, Y., Lee, R., Sahu, S.: Predicting the performance of concrete structures exposed to chemically aggressive environment - field validation. Materials and Structures $\mathbf{3 5}(10)$, 623-631 (2002). DOI 10.1007/BF02480355. URL http://dx.doi.org/10.1007/BF02480355

26. Martín-Pérez, B., Zibara, H., Hooton, R., Thomas, M.: A study of the effect of chloride binding on service life predictions. Cement and Concrete Research 30(8), 1215 - 1223 (2000). DOI http://dx.doi.org/10.1016/S0008-8846(00)00339-2. URL http://www.sciencedirect.com/science/article/pii/S0008884600003392

27. Nelder, J.A., Mead, R.: A simplex method for function minimization. The Computer Journal 7(4), 308-313 (1965). $\quad$ DOI $10.1093 /$ comjn1/7.4.308. $\quad$ URL http://comjnl.oxfordjournals.org/content/7/4/308.abstract

28. Nguyen, T.Q., Baroghel-Bouny, V., Dangla, P.: Prediction of chloride ingress into saturated concrete on the basis of a multi-species model by numerical calculations. Computers and Concrete 3, 401-422 (2006)

29. Nguyen, T.S.: Influence of the nature of the binder and the temperature on the transport of chlorides in cementitious materials (in French). Ph.D. thesis, INSA Toulouse (2006)

30. Nielsen, E.P., Geiker, M.R.: Chloride diffusion in partially saturated cementitious material. Cement and Concrete Research 33(1), 133 - 138 (2003). DOI http://dx.doi.org/10.1016/S0008-8846(02)00939-0. URL http://www.sciencedirect.com/science/article/pii/S0008884602009390

31. Nilsson, L., Sandberg, P., Poulsen, E., Tang, L., Andersen, A., Frederiksen, J.: Hetek, a system for estimation of chloride ingress into concrete. theoritical background. The Danish Road Directorate Report No.83 (1997)

32. Paz-García, J.M., Johannesson, B., Ottosen, L.M., Ribeiro, A.B., Rodríguez-Maroto, J.M.: Computing multi-species chemical equilibrium with an algorithm based on the reaction extents. Computers \& Chemical Engineering 58(0), 135 - 143 (2013). DOI http://dx.doi.org/10.1016/j.compchemeng.2013.06.013. URL http://www.sciencedirect.com/science/article/pii/S009813541300207X

33. Ramachandran, V.: Possible states of chloride in the hydration of tricalcium silicate in the presence of calcium chloride. Materials and Structures 4(1), 3-12 (1971). DOI 10.1007/BF02473926. URL http://dx.doi.org/10.1007/BF02473926

34. Saillio, M.: Physical and chemical binding in non-carbonated and carbonated cement materials. influence on the ion transport. Ph.D. thesis, (In French), Université Paris-Est-Marne-la-Vallée (2012)

35. Saillio, M., Baroghel-Bouny, V., Barberon, F.: Chloride binding in sound and carbonated cementitious materials with various types of binder. Construction and Building Materials 68(0), 82 - 91 (2014). DOI http://dx.doi.org/10.1016/j.conbuildmat.2014.05.049. URL http://www.sciencedirect.com/science/article/pii/S0950061814005339

36. Samson, E., Marchand, J., Beaudoin, J.: Describing ion diffusion mechanisms in cementbased materials using the homogenization technique. Cement and Concrete Research 29(8), 1341 - 1345 (1999). DOI http://dx.doi.org/10.1016/S0008-8846(99)00101-5. URL http://www.sciencedirect.com/science/article/pii/S0008884699001015

37. Suryavanshi, A., Scantlebury, J., Lyon, S.: Mechanism of friedel's salt formation in cements rich in tri-calcium aluminate. Cement and Concrete Research 26(5), 717 - 727 (1996). DOI http://dx.doi.org/10.1016/S0008-8846(96)85009-5. URL http://www.sciencedirect.com/science/article/pii/S0008884696850095

38. Tang, L.: Guidelines for practical use of methods for testing the resistance of concrete to chloride ingress. EU-Project CHLORTEST (EU funded research Project under 5FP GROWTH programme), SP Swedish National, Testing and Research Institute, Boras, Sweden 271, - (2005)

39. Tang, L.: Engineering expression of the clinconc model for prediction of free and total chloride ingress in submerged marine concrete. Cement and Concrete Research 38(89), 1092 - 1097 (2008). DOI http://dx.doi.org/10.1016/j.cemconres.2008.03.008. URL http://www.sciencedirect.com/science/article/pii/S0008884608000720

40. Tang, L., Andersen, A.: Chloride ingress data from five years fild exposure in a swedish marine environment. In: C. Andrade, J. Kropp (eds.) Second International RILEM Workshop on Testing and Modelling the Chloride Ingress into Concrete, pp. 105-119. RILEM Publications SARL (2000)

41. Tang, L., Nilsson, L.O.: Chloride binding capacity and binding isotherms of $\{\mathrm{OPC}\}$ pastes and mortars. Cement and Concrete Research 23(2), 247 - 253 (1993). DOI http://dx.doi.org/10.1016/00088846(93)90089-R. URL http://www.sciencedirect.com/science/article/pii/000888469390089R

42. Tritthart, J.: Chloride binding in cement ii. the influence of the hydroxide concentration in the pore solution of hardened cement paste on chloride binding. Cement and Concrete Research 19(5), 683 - 691 (1989). DOI http://dx.doi.org/10.1016/0008-8846(89)90039-2. URL http://www.sciencedirect.com/science/article/pii/0008884689900392

43. Truc, O., Ollivier, J., Carcasss, M.: A new way for determining the chloride diffusion coefficient in concrete from steady state migration test. Cement and Concrete Research 
30(2), 217 - 226 (2000). DOI http://dx.doi.org/10.1016/S0008-8846(99)00232-X. URL http://www.sciencedirect.com/science/article/pii/S000888469900232X

44. Truc, O., Ollivier, J.P., Nilsson, L.O.: Numerical simulation of multi-species transport through saturated concrete during a migration test msdiff code. Cement and Concrete Research 30(10), 1581 - 1592 (2000). DOI http://dx.doi.org/10.1016/S0008-8846(00)00305-7. URL http://www.sciencedirect.com/science/article/pii/S0008884600003057

45. Wang, H., Gillott, J.: Mechanism of alkali-silica reaction and the significance of calcium hydroxide. Cement and Concrete Research 21(4), 647 - 654 (1991). DOI http://dx.doi.org/10.1016/00088846(91)90115-X. URL http://www.sciencedirect.com/science/article/pii/000888469190115X

46. Yuan, Q., Shi, C., Schutter, G.D., Audenaert, K., Deng, D.: Chloride binding of cement-based materials subjected to external chloride environment a review. Construction and Building Materials 23(1), 1 - 13 (2009). DOI http://dx.doi.org/10.1016/j.conbuildmat.2008.02.004. URL http://www.sciencedirect.com/science/article/pii/S095006180800055X

47. Zhang, T., Gjorv, O.E.: Effect of ionic interaction in migration testing of chloride diffusivity in concrete. Cement and Concrete Research 25(7), 1535 - 1542 (1995). DOI http://dx.doi.org/10.1016/00088846(95)00147-5. URL http://www.sciencedirect.com/science/article/pii/0008884695001475 